\title{
Life Cycle of the QBO-modulated 11-year Solar Cycle Signals in the Northern Hemispheric Winter
}

Hua Lu ${ }^{1}$, Lesley J. Gray ${ }^{2}$, Mark P. Baldwin ${ }^{3}$, Martin J. Jarvis ${ }^{1}$

Revised for Quarterly Journal of the Royal Meteorological Society

2009-01-30

\footnotetext{
${ }^{1}$ H. Lu and M. J. Jarvis, Physical Sciences Division, British Antarctic Survey, High Cross, Madingley Road, Cambridge CB3 0ET, England, UK. (email: hlu@bas.ac.uk; mjja@bas.ac.uk )

2 L. J. Gray, NCAS-Climate, Meteorology Dept., Reading University, Earley Gate, PO Box 243, Reading RG6 6BB, UK. (email: lesley@met.rdg.ac.uk)

${ }^{3}$ M. P. Baldwin, Northwest Research Associates, 4118, $148^{\text {th }}$ Ave, Redmond, WA 98052, USA. (email: mark@nwra.com)
} 
Abstract: This paper provides some insights on the Quasi-Biennial Oscillation (QBO) modulated 11year solar cycle (11-yr SC) signals in northern hemispheric (NH) winter temperature and zonal wind. Daily ERA-40 and ECMWF Operational data for the period of 1958-2006 were used to examine the seasonal evolution of the QBO-solar cycle relationship at various pressure levels up to the stratopause. The results show that the solar signals in the NH winter extratropics are indeed QBO-phase dependent, moving poleward and downward as winter progresses with a faster descent rate under westerly QBO than under easterly QBO. In the stratosphere, the signals are highly significant in late January to early March and have a life span of 30-50 days. Under westerly QBO, the stratospheric solar signals clearly lead and connect to those in the troposphere in late March and early April where they have a life span of 10 days. As the structure changes considerably from the upper stratosphere to the lower troposphere, the exact month when the maximum solar signals depends occur largely on the altitude chosen.

For the low latitude stratosphere, our analysis supports a vertical double-peaked structure of positive signature of the 11-yr SC in temperature and demonstrates that this structure is further modulated by the QBO. These solar signals have a longer life span ( 3-4 months) in comparison to those in the extratropics. The solar signals in the lower stratosphere are stronger in early winter but weaker in late winter, while the reverse holds in the upper stratosphere. 


\section{Introduction}

Studies have shown that the Northern Hemisphere (NH) winter temperature and circulation may be influenced by both the quasi-biennial oscillation (QBO) of the equatorial lower stratosphere (Holton and Tan 1980; Naito et al. 2003) and the 11-year solar cycle (11-yr SC) (Labitzke 1987; Labitzke and van Loon 1988; Kodera and Kuroda 2002). It has been showed that, on average, when the equatorial winds near $50 \mathrm{hPa}$ are easterly, the $\mathrm{NH}$ polar winter in the lower stratosphere tends to be warmer and the polar vortex becomes more disturbed, and vice versa when the equatorial winds are westerly (Holton and Tan 1980; 1982; Naito et al. 2003; Lu et al. 2008).

However, Labitzke (1987) suggested a more complicated, nonlinear interaction between the QBO and the 11-yr SC, and found that the north polar temperature at $30 \mathrm{hPa}$ is positively correlated with the 11-yr SC when the QBO is westerly (wQBO), and negatively correlated when the QBO is easterly (eQBO). Thus, at solar maximum, the $\mathrm{NH}$ polar vortex appears to be opposite to the Holton and Tan (HT) relationship. Using a 30-year (1956-1986) stratospheric dataset of the Freie Universität Berlin (FUB), Labitzke and van Loon (1988) expanded the work of Labitzke (1987) and found similar correlations exist between the 11-yr solar cycle and January/February averaged polar temperature and geopotential heights at $30 \mathrm{hPa}$. They found that Sudden Stratospheric Warmings (SSWs) are more prevalent in low solar (LS) years during the eQBO phase and in high solar (HS) years during the wQBO phase, suggesting that the HT relationship is reversed during HS years. Naito and Hirota (1997) updated their study using a 37year (1958-1994) stratospheric temperature dataset of the Free University of Berlin (FUB) combined with a 31-year (1963-1994) National Meteorological Centre (NMC) global zonal- 
mean zonal wind data set and confirmed that the "reversed" behavior found by Labitzke and van Loon (1988) held over this extended period. Gray et al. (2001) examined radiosonde equatorial winds and polar temperature data for 1955-1999 and found a negative correlation between lower stratospheric equatorial winds and NH polar stratospheric temperature, indicating a strong HT relationship only during LS years, and a very weak positive correlation during HS years. They consequently suggested that the HT relationship is weakened during solar maximum but not necessarily reversed.

This QBO-SC relationship has been re-examined and confirmed more recently by several authors using reanalysis data (Labitzke and van Loon 2000; Labitzke 2001, 2004, 2005; Salby and Callaghan 2006). Labitzke et al. (2006) (hereafter LKB2006) used the NCEP/NCAR reanalysis data from 1958 to 2006 combined with earlier data from statistical reconstructions based on historical upper air data, thus extending the data period to 65 years (1942-2006). This new analysis, which concentrated on February in the NH winter and July in the Southern Hemisphere (SH) winter, confirmed their earlier results.

Studies have shown that variations in 11-yr solar irradiance and subsequent UV absorption by ozone cause changes in temperature and wind in the upper stratosphere (Hood 2004; Crooks and Gray 2005). These relatively weak direct changes could alter the upward propagation of planetary-scale waves, and lead to an indirect feedback on the lower atmosphere through a modulation of the polar-night jet as well as through a change of the stratospheric mean circulation - Brewer-Dobson (BD) circulation (Kodera and Kuroda 2002). The change in BD circulation may also influence the transport of ozone to the lower stratosphere (Hood 2004), which will also cause temperature and wind variations in the lower stratosphere due to diabatic heating (e.g., Gray et al. 2009). Finally, a direct modulation of the equatorial QBO descent rates 
by the SC has been proposed (McCormack 2003; Pascoe et al. 2005; McCormack et al. 2007). However, it is not clear which of these, if any, is the dominant mechanism for QBO-SC interaction.

The mechanism by which the QBO modulates the solar responses in the polar stratosphere during the NH winter is still not understood. More specifically, it is not clear why the QBO-SC influence on NH extratropical circulation and SSWs appears to be strong primarily in February (LKB2006). The main purpose of this paper is to further examine the QBO-SC relationship over the whole of the $\mathrm{NH}$ winter, with a strong emphasis on its intra-seasonal life cycle and the interaction between the equator and polar region. To study when and where the solar signals are initialized, strengthened, and finally weakened, the five winter months from November to March are examined using monthly and sub-monthly averages of temperature and zonal wind. We examine whether the relationship holds coherently over several months, whether the relationship is statistically significant and how the solar signals move in altitude and latitude through the winter.

\section{Data and Methods}

The data used are daily mean zonal winds and temperatures from the ECMWF (European Centre for Medium Range Weather Forecasting) ERA-40 Reanalysis (September 1957 to August 2002) and ECMWF Operational analyses (September 2002 to December 2006). Both datasets extend to $1 \mathrm{hPa}(\sim 50 \mathrm{~km})$, thus allowing an examination of the solar signals throughout the stratosphere. The daily data have not previously been used for this purpose and this work is therefore complementary to earlier analyses (e.g., LKB2006 and Gray et al. (2004)) by providing more detailed temporal information of the QBO-SC relationship. The ERA-40 Reanalysis has a 
spectral resolution of T159, corresponding to a $1.125^{\circ}$ horizontal resolution in latitude and longitude. The data are available at 23 standard pressure surfaces from $1000 \mathrm{hPa}$ to $1 \mathrm{hPa}$, which were assimilated using direct radiosonde and satellite measurements (Uppala et al. 2005). The ECMWF Operational data were output from the ongoing analyses produced by the most recent ECMWF Integrated Forecasting System (IFS) model. Data from September 2002 to the present day are available on the same $1.125^{\circ}$ grid and on 21 pressure levels, which are identical to the ERA-40 data except without the 600 and 775 hPa levels. For consistency, only the data for those 21 pressure levels are used here.

The QBO was defined using the deseasonalized zonal wind from the blended ERA40 and Operational data at $0.56^{\circ} \mathrm{N}, 50 \mathrm{hPa}$ to be consistent with previous work (Holton and Tan 1980; Labitzke and van Loon 1988). The phase of the QBO was determined for each specific period after an average window was applied to both the QBO and the atmospheric variable it correlates to. Transition periods when the absolute values of the QBO were smaller than $2 \mathrm{~m} \mathrm{~s}^{-1}$ were excluded from the analysis. Qualitatively similar results were obtained if the phase of the QBO is defined only for those winters for which the same phase of the QBO remains throughout. Slightly weaker but oppositely-signed solar signals are obtainable if the deseasonalized zonal wind at $5 \mathrm{hPa}$ is used to define the QBO phase. Qualitatively similar results can also be obtained if the QBO phase is defined by zonal wind measurements from equatorial radiosondes at 40-50 hPa. However, much weaker correlations are found when other QBO levels were used.

Possible contamination by the temporary heating caused by volcanic aerosols in the stratosphere was examined by excluding or including two years of data following three major eruptions (i.e. Agung in March, 1963, El Chichón in March, 1982, and Pinatubo in June, 1991). Qualitatively similar results were obtained for the spatial pattern and significances of the solar 
signals in either case. In the results reported below, all winter data are included, to be consistent with LKB2006.

Following previous studies, $10.7-\mathrm{cm}$ solar radio fluxes (in units of $10^{-22} \mathrm{Wm}^{-2} \mathrm{~Hz}^{-1}$ ) are used as a proxy for the 11-yr SC. Daily observed 10.7-cm solar radio fluxes were obtained from the National Geophysical Data Center (NGDC) website (www.ngdc.noaa.gov/stp). Most previous studies have used 1-month to 2-month averaged 10.7-cm solar radio fluxes. We tested and examined 1-month through 12-month averaged 10.7-cm solar radio fluxes preceding the day when the atmospheric variable averages were taken, and only found $~ 10 \%$ of variation in correlation coefficients and an even smaller amount of change in spatial coverage of the solar signals. This suggests that the signals reported in this paper are mostly due to low frequency variations (i.e. 11-yr cycle) in solar inputs. Although qualitatively similar results are obtained using any averaging period from 1-month to 12-months, we have employed 6-month averaged 10.7- $\mathrm{cm}$ solar radio fluxes $\left(\mathrm{F}_{\mathrm{s}}\right.$ hereafter) since this gives the most consistent results with the highest overall correlation coefficients and statistical confidence levels. More specifically, all the solar signals reported below were results from using 6-month averaged 10.7-cm solar radio fluxes preceding the day when the atmospheric variable averages were taken.

The main diagnostic tools employed are linear correlation and composite analysis. The statistical confidence levels of the correlations are calculated using the standard Student t-test. The same Monte Carlo significance test used by Lu et al. (2007) is used to test the statistical significance of the composite differences.

\section{Results}

\subsection{Solar signals in the $\mathrm{NH}$ polar region}


In agreement with previous studies (e.g., LKB2006), no significant correlation between $\mathrm{F}_{\mathrm{s}}$ and atmospheric temperatures in November to January was found in the NH polar region when monthly-averaged temperatures were employed, but significant solar signals are found in February and March. Figure 1 shows the latitude-height cross-section of the correlation between 6-month averaged F10.7-cm solar radio fluxes $\left(\mathrm{F}_{\mathrm{s}}\right)$ and monthly mean temperature in the NH for February and March, for the period 1958 to 2006. In the NH polar stratosphere, rather weak positive solar signals with maximum correlation coefficient $r_{\max }=0.3$ emerge only in February when all years are used (upper-left panel), while significantly stronger signals appear in the NH polar region when the data are separated into wQBO and eQBO (middle and right-hand columns). In February, a large area of the Arctic lower stratosphere (57 $\left.-90^{\circ} \mathrm{N}, 20-300 \mathrm{hPa}\right)$ exhibits significant positive correlations under wQBO, while significant negative correlations are found at the lower most stratosphere $\left(70^{\circ}-90^{\circ} \mathrm{N}, 100-300 \mathrm{hPa}\right)$ under eQBO. For the both QBO phases, oppositely-signed solar signals to those in the Arctic lower stratosphere are found in the Arctic upper stratosphere though the signals associated with wQBO appear at a higher altitude than those associated with eQBO. In March, positive correlations are found $\left(60^{\circ}-80^{\circ} \mathrm{N}, 100-200\right.$ $\mathrm{hPa}$ ) and negative correlations occur at around $70^{\circ}-90^{\circ} \mathrm{N}, 10 \mathrm{hPa}$ under wQBO. Weak negative correlations are found at around $70^{\circ}-90^{\circ} \mathrm{N}, 150-200 \mathrm{hPa}$, and significant positive correlations are found at around $40^{\circ}-60^{\circ} \mathrm{N}, 30-100 \mathrm{hPa}$ under eQBO. Comparing to those in February, the correlation patterns in March imply possible descent of the solar signals.

\section{[[Insert Figure 1 here]]}

The solar signals in February temperature compare exceedingly well with LKB2006. The deep positive solar signals in the polar stratosphere under wQBO at 10-250 hPa have a maximum correlation coefficient of $r_{\max }=0.82$ in this study compared with $r_{\max }=0.6$ in LKB2006. This is 
partially due to the fact that we use 6-month averaged $F_{s}$ while LKB2006 used monthly mean $F_{s}$. It may also be partially due to the use of less reliable data pre-1958 by LKB2006. The dipolar structure shown here over the pole under eQBO is again similar to that in LKB2006, who, because they used data extending vertically only up to $10 \mathrm{hPa}$, were only able to show a hint of the positive correlation above $\sim 20 \mathrm{hPa}$. In the current study this region of positive correlation reaches its maximum correlation coefficient of 0.65 near $5 \mathrm{hPa}$.

To show the temporal evolution of the solar signals, Figure 2 plots the time series of deseasonalized February temperatures $\mathrm{T}_{\mathrm{Feb}}$ against $\mathrm{F}_{\mathrm{s}}$ Aug-Jan at $85^{\circ} \mathrm{N}, 50 \mathrm{hPa}$, under wQBO, and at $85^{\circ} \mathrm{N}, 200 \mathrm{hPa}$, under eQBO. These locations represent maximum and minimum correlation coefficients in the lower stratosphere under wQBO and eQBO respectively in February (see Figure 1). It shows that the positive correlation under wQBO attains $r=0.82$ with a confidence level of 99.9\%. Similarly, the negative correlation under eQBO has $r=-0.62$ with a confidence level of 99.2\%. There are very few eQBO years in the 1990s, resulting in fewer data points around this period. 1999/2000 winter under wQBO and 1971/1972, 1974/1975, 1996/1997, 2001/2002 winters under eQBO appear to be anomalous for the correlations. The results agree qualitatively with Labitzke and van Loon (1988) and Gray et al. (2001), who used Jan-Feb averaged temperatures at $\sim 30 \mathrm{hPa}(24 \mathrm{~km})$ at the North Pole and Jan-Feb mean F10.7-cm solar radio fluxes.

\section{[[Insert Figure 2 here]]}

Figure 3 shows the correlation between $\mathrm{F}_{\mathrm{s}}$ and monthly-mean zonal mean zonal wind in February and March. A similar dependence on the QBO phase is also evident. When all years are used, weak negative solar signals ( $r_{\max }=0.4$, confidence levels $\geq 95 \%$ ) appear in the Arctic upper stratosphere in February, while no significant correlation can be found in March. Similar 
to the solar signals in the temperature, clearer and much stronger solar signals appear when the data are separated into wQBO and eQBO. In February and under wQBO, the entire stratospheric extratropics are covered by negative correlations ( $r_{\max }=0.7$, confidence levels $\geq 95 \%$ ), indicating that the stratospheric polar vortex is more disturbed at HS and more stable at LS. Under eQBO, positive signals are found in the Arctic lower stratosphere and around $55^{\circ}-70^{\circ} \mathrm{N}$ in the troposphere while negative signals appear at mid-latitudes extending from the surface to the upper stratosphere. From February to March, the high latitude negative correlations in wQBO years descend from around 1-100 hPa to 30-1000 hPa, and the centre of the positive correlations in eQBO years move poleward and downward from around $10-200 \mathrm{hPa}$ and $60^{\circ} \mathrm{N}$ to $100-1000$ hPa and $75^{\circ} \mathrm{N}$.

\section{[[Insert Figure 3 here]]}

Similar to Figure 2, Figure 4 plots the time series of deseasonalized February zonal wind $\mathrm{U}_{\mathrm{Feb}}$ against $\mathrm{F}_{\mathrm{s}}$ Jul-Jan at $70^{\circ} \mathrm{N}, 10 \mathrm{hPa}$ in the wQBO phase and at $70^{\circ} \mathrm{N}, 100 \mathrm{hPa}$ in the eQBO phase. Those locations represent minimum and maximum correlation coefficients in February under wQBO and eQBO respectively (see Figure 3). Under wQBO, the correlation is -0.78 , significant at the $99.8 \%$ confidence level. Under eQBO, the correlation is 0.62 , significant at the $99.2 \%$ confidence level. Similar to Figure 2, 1999/2000 winter under wQBO and 1974/1975, 1996/1997, 2001/2002 winters under eQBO appear to be anomalous.

\section{[[Insert Figure 4 here]]}

Further sensitivity studies using data from different time periods gave qualitatively similar results for those QBO-modulated solar signals in the high latitudes shown in Figures 1 and 3. Including or excluding the years affected by volcanic eruptions also makes little change to the 
general features of the signals. In addition, linear de-trending or removing the lower frequency components does not alter the general spatial patterns and confidence levels. This agrees well with Salby and Callaghan (2006) who also found that the QBO-SC relationship during February primarily exists in the high frequency component of the temperature.

The fact that the time series of the ENSO and F10.7-cm solar flux $\mathrm{F}_{\mathrm{s}}$ is only weakly correlated helps to rule out a linear contamination of QBO-SC relationship by the ENSO. However, it does not rule out the possibility that the ENSO might modulate the QBO-SC relationship through non-linear processes. It is interesting to note that all the anomalous winters shown in Figures 3 and 4 happened to be when the El Niño/Southern Oscillation (ENSO) was in its deep La-Niña phase, identified as those winters for which the Dec-Feb NINO3.4 exceeds its 0.5 standard deviations (see http://cses.washington.edu/cig/pnwc/compensopdo.shtml). Camp and Tung (2007) found that, during Dec-Feb, zonal mean temperature in the polar stratosphere at 10$50 \mathrm{hPa}$ was $4^{\circ} \mathrm{K}$ warmer in the El-Niño years than in the La Niña years, while no significant ENSO signals were detectable at low latitudes. By using two different GCMs, García-Herrera et al. (2006) showed that the ENSO signature in zonal mean temperature in the Arctic stratosphere was characterized by a gradually descending dipole pattern with a negative cell in the upper stratosphere and positive cell in the mid- to lower stratosphere and it is most significant in $\mathrm{NH}$ winter. They showed that vertical wave propagation and divergence of Eliassen-Palm flux were noticeably enhanced in mid-latitudes of the NH during El-Niño winters, and the enhanced wave driving force a stronger BD-circulation in the stratosphere and cause cooling in the tropical lower stratosphere and warming at higher latitudes. Comparing Figure 1 to Fig. 13 of García-Herrera et al. (2006), the pattern of ENSO signature derived from the GCMs is quite similar to the solar signals under wQBO, while the ENSO signature derived from ERA40 data shows a vertically 
reversed pattern similar to the solar signals under eQBO. The ENSO signature shown by GarcíaHerrera et al. (2006) was based on data in 1997-1999 when the ENSO was anomalously more positive. It is therefore hard to tell how ENSO might affect longer term variation of the QBO-SC relationship as the stratosphere polar vortex responses to the QBO, solar and ENSO involve nonlinear interaction between zonal wind and waving forcing and their further impact on the residual circulation (Holton and Tan 1980; 1982; Kodera and Kuroda 2002; García-Herrera et al. 2006).

For fixed latitudes with a higher temporal resolution, Figure 5 shows running correlations between $\mathrm{F}_{\mathrm{s}}$ and an 11-day averaged temperature at $90^{\circ} \mathrm{N}$ (upper panels), and zonal-mean zonal wind anomaly at $80^{\circ} \mathrm{N}$ (lower panels), under wQBO (left-hand panels) and eQBO (right-hand panels). The correlations are plotted at the $6^{\text {th }}$-day of the 11-day averages and all available data since 1958 are used. It shows that, under wQBO, the positive solar signals in the polar temperature descend from $10 \mathrm{hPa}$ to $300 \mathrm{hPa}$ from late January to mid-March while the negative signals descend from $1 \mathrm{hPa}$ to $30 \mathrm{hPa}$ from mid-February to early April. Under eQBO, a similar downward propagating behavior is seen in the temperature correlations, except that the correlations are approximately opposite in sign to those under wQBO and appear to have a slower descent rate. The wind correlations follow the pattern of the temperature correlations. Under wQBO, the solar signals in the polar zonal-mean zonal wind are characterized by a downward descent of negative correlations from $1 \mathrm{hPa}$ to the surface and from middle January to middle March, while under eQBO, they are characterized by positive correlations from $10 \mathrm{hPa}$ to $100 \mathrm{hPa}$ and from early February to early March. The tropospheric signals under eQBO emerge in late March and appear to be disconnected to those from the stratosphere. Note that qualitatively similar correlation patterns can be obtained by selecting any latitude from $70^{\circ} \mathrm{N}$ to $90^{\circ} \mathrm{N}$ and using any running window in the range from 7-days to 40-days. Similar results can 
also be obtained if only the data since September 1978 are used. The solar signals in the NH polar region are found to have a life span of 30-50 days, which is similar to the thermal relaxation time scale in the lower stratosphere (Newman and Rosenfield 1997). In the troposphere, the life span of solar signals is about 10 days.

\section{[[insert Figure 5]]}

From Figure 5, it is immediately evident why such a large signal is seen in the monthlyaveraged analysis in February/March under wQBO, due to the timing of the anomaly across the monthly boundaries. In the wQBO phase, the positive temperature correlations (top left panel) appears almost simultaneously at all heights from $1 \mathrm{hPa}$ down to $300 \mathrm{hPa}$ through January. This is consistent with a higher frequency of SSWs in solar maximum wQBO years (Labitzke and van Loon 1988; LKB2006). SSWs are initiated over a period of a few days, giving rise to anomalously warm conditions and the destruction of the vortex throughout the depth of the stratosphere. The subsequent recovery to westerly/colder conditions is governed by radiative cooling (Limpasuvan et al. 2004), the timescale of which depends on height; the polar vortex recovers first at upper levels where the radiative timescale is relatively short ( days), but in the lower stratosphere where radiative timescales are much longer, full recovery of the vortex takes correspondingly longer, thus explaining the gradual descent of the negative temperature correlations from 1 hPa in early February to 100 hPa in mid-March.

The negative signals under eQBO in the lower stratosphere may correspond to more SSWs occurring in mid-winter of the LS/eQBO years. The weaker correlations earlier in the winter suggest more disturbed conditions with less 11-yr SC influence, in agreement with previous studies (Baldwin and Dunkerton 1998; Gray et al. 2004). From mid-January at the $1 \mathrm{hPa}$ level to March, strong positive signals appear in the upper stratosphere. These upper stratospheric signals 
are either due to subsequent recovery to westerly/colder conditions following the SSWs in midwinter of the LS/eQBO years, or a result of warmer response in temperature at HS similar to those under wQBO. If the latter case holds true, a QBO perturbation on the solar signals in the Arctic winter should be primarily confined in the lower stratosphere.

In the troposphere, there are also significant correlations under both QBO phases, especially in the zonal wind fields during March, possibly due to weaker winds in HS/wQBO years and LS/eQBO years. The correlations occur almost simultaneously at all heights below $\sim 200 \mathrm{hPa}$ in the wind fields and $\sim 300 \mathrm{hPa}$ in the temperature fields. This height dependence is similar to that of the northern annular mode (NAM) anomalies (Baldwin and Dunkerton 2001) and is likely to reflect the faster timescales of the typical dynamical processes in the troposphere.

Correlation analysis has been performed of $\mathrm{F}_{\mathrm{s}}$ against progressing quasi-10-day averages of temperature and zonal wind in the latitude-height cross section. Figure 6 shows the correlation between quasi-10-day averages of temperature in the $\mathrm{NH}$ and $\mathrm{F}_{\mathrm{s}}$ preceding the date when the quasi-10-day temperature averaging starts, for the five winter months from November to March. The data are also grouped according the phases of the QBO. Qualitatively similar results are obtainable if 5- to 20-day averages are used. Note that the use of quasi-10-day averages is only to facilitate an easier discussion of the results because the patterns can be described as early, middle and late solar signals for a given calendar month. The lack of radiosonde measurements in the upper stratosphere may result in unreliable estimations before the satellite era (i.e. preSeptember 1978). For this reason, results from data since September 1978 are reported below. Discussions on sensitivity of the results to the period chosen are also made.

\section{[[Insert Figure 6 here]]}


Figure 6 shows that, under wQBO, no solar signature can be found in polar temperature from $1^{\text {st }}$ November to $20^{\text {th }}$ January. Highly significant positive correlations start to appear during $21^{\text {st }}$. $31^{\text {st }}$ January in the extratropical upper stratosphere $(2-8 \mathrm{hPa})$. From that time forward, those positive signals move slightly poleward but noticeably downward and finally descend into the polar troposphere in the $11^{\text {th }}-20^{\text {th }}$ March panel. Simultaneously, significant poleward movement of the solar signals can be noticed near the equator in the upper stratosphere. Starting from the $1^{\text {st }}$ $-10^{\text {th }}$ February panel, significant positive correlations start to build up near the equator at $\sim$ 3hPa and then disperse poleward reaching $40^{\circ} \mathrm{N}$ in the $10^{\text {th }}-20^{\text {th }}$ March panel.

Under eQBO, again no clear solar signature is found in the extratropical stratosphere from $1^{\text {st }}-10^{\text {th }}$ November to $11^{\text {th }}-20^{\text {th }}$ December. Negative correlations start to build up in the lower polar stratosphere from $21^{\text {st }}-31^{\text {st }}$ December and they remain in the region until $1^{\text {st }}-10^{\text {th }}$ March and ease away after then. Clear positive solar signals appear in the extratropical upper stratosphere in late January. Under eQBO, the solar signals appear to descend more slowly than those under wQBO. They remain above $30 \mathrm{hPa}$ until $11^{\text {th }}-20^{\text {th }}$ March after which they rapidly diminish and exhibit no noticeable poleward propagation.

Significant positive correlations are also present in the low to middle latitudes. In the lower stratosphere subtropics to mid-latitudes $\left(20^{\circ}-50^{\circ} \mathrm{N}, 20-100 \mathrm{hPa}\right)$, positive correlations are found throughout all winter months up to the beginning March under wQBO. Under eQBO, during February strong positive correlations are present in the equatorial tropical latitudes, which are simultaneously accompanied by negative correlation in the subtropics, suggesting a modulation of the Hadley circulation (Haigh 1996, 1999).

Figure 7 shows the corresponding zonal-mean zonal wind analysis. Under wQBO, there is no significant correlation until early January in the polar region, while significant positive 
correlations appear in the extratropical lower stratosphere with negative correlations at midlatitudes in the $11^{\text {th }}-20^{\text {th }}$ January panel. Noticeable negative correlations appear in the subtropical to mid-latitude upper stratosphere in the $21^{\text {st }}-31^{\text {st }}$ January panel. By $1^{\text {st }}-10^{\text {th }}$ February, the center of these correlations has moved poleward from $35^{\circ} \mathrm{N}$ to $60^{\circ} \mathrm{N}$, and by $11^{\text {th }}-20^{\text {th }}$ February, it has descended from $3 \mathrm{hPa}$ to $30 \mathrm{hPa}$. From then, the downward propagation continues and it reaches the polar troposphere in the $11^{\text {th }}-20^{\text {th }}$ March panel. Concurrently, significant positive correlations build up in the mid-latitude upper stratosphere in early February and propagate more slowly poleward and downward until $11^{\text {th }}-20^{\text {th }}$ March. Near the equator, significant negative solar signals are found at $\sim 2-5 \mathrm{hPa}$ as early as $1-10^{\text {th }}$ December, implying that the equatorial and subtropical zonal winds become more easterly under HS than under LS, and these remain throughout the winter.

\section{[[Insert Figure 7 here]]}

Under eQBO and in the polar region, though positive correlations appear in the polar stratosphere across the winter months, they are mostly not significant at the 95\% confidence level. From $11^{\text {th }}-31^{\text {st }}$ January, negative correlations build up in the upper stratospheric subtropics and remain there until early February. In February, these negative correlations are noticeably enhanced and significant correlations are extended into the mid-latitude upper stratosphere and troposphere. It is apparent that poleward propagation of the negative solar signals in the upper stratosphere is simultaneously accompanied by a strengthening of the positive-negative-positive (from equator to the pole) pattern of correlations in the troposphere. From middle January to late February, significant positive correlations appear in the tropical and subtropical troposphere; generally opposite to those shown under wQBO. The correlation pattern in the equatorial to the subtropical troposphere under eQBO implies weaker westerlies in the equatorial flank of the 
Hadley cell and stronger westerlies in its poleward flank at HS. The negative then positive latitudinal correlation pattern in the extratropical region in February suggests a negative Northern Annular Mode (NAM) at HS, which is found to be associated with a warmer polar vortex (Thompson and Wallace 1998; Baldwin 2001); this is consistent in terms of thermal wind balance in relation to the solar signals in temperature shown in Figure 6. In comparison to those under wQBO, the strongest correlations are found in low to middle latitudes rather than near the pole, and its descent rate in the polar region is noticeably slower under eQBO than under wQBO. This implies that dynamic responses to the 11-yr SC in the lower stratosphere are stronger in the polar region under wQBO and in the extra-polar region under eQBO, supporting the conclusions of previous studies (Labitzke 2005; Lu et al. 2007). However, our results shown in Figures 5-7 differ from Kodera and Kuroda (2002), who found that westerly anomalies associated with the upper stratospheric subtropical jet moved poleward and downward under HS in early winter. We find that the early winter solar signals are no longer significant when more data are used.

\subsection{Solar signals at low latitudes}

It is known that the tropics and extratropics are linked through the BD circulation, with upwelling in the tropics and downwelling in the polar region. In the lower stratosphere, anomalous warming in the polar region is likely to be compensated by cooling in the subtropics and mid-latitudes, due to the associated strengthening of the BD circulation. In order to investigate any possible interaction between tropical solar forcing and extratropical responses, in this section, we focus on temperature variations in the equatorial to subtropical region of the stratosphere. The 2-month averages are used for the atmospheric variables as we found that the signals at low latitudes are of lower frequency than those at highly latitudes. 
Figure 8 shows the composite differences between HS and LS conditions of Dec-Jan and Feb-Mar mean temperatures (using data from September 1978 onwards). The solar signal in stratospheric equatorial temperature during Dec-Mar essentially has a double-peaked vertical profile with the upper peak near 2-3 $\mathrm{hPa}$ and the lower peak at $\sim 50 \mathrm{hPa}$; the signals are approximately symmetric about the equator. The temperature is up to $3 \mathrm{~K}$ higher in the upper stratosphere and up to $1.5 \mathrm{~K}$ higher in the mid-latitude lower stratosphere at HS than at LS. However, in the region of $25^{\circ}-55^{\circ} \mathrm{N}$ in the upper stratosphere, up to $3 \mathrm{~K}$ reduction in temperature is found. The pattern of solar cycle temperature differences is consistent with the studies of Haigh (2003), Crooks and Gray (2005), and Kekhut et al. (2005), although the amplitudes are larger. This may be due to a contribution from the volcanic disturbances in the lower stratosphere but it is unlikely to be a factor in the upper stratosphere. A close examination of the statistical confidence levels suggests that the positive solar signature in the upper stratosphere achieves higher statistically confidence levels in Feb-Mar than in Dec-Jan, while the opposite holds for the signals in the lower stratosphere.

\section{[[Insert Figure 8]]}

On the time scale associated with SSWs, temporal tendencies in tropical column ozone and temperature correlate inversely with the strength of planetary wave absorption at northern middle to high latitudes (Randel 1993). Randel et al. (2002) showed that the positive effect of extratropical wave forcing on tropical upwelling exists from timescales ranging from weekly to seasonal. In comparison to those early winter signals, the relatively weaker solar signals near the equatorial lower stratosphere in late winter are likely due to stronger wave forcing in the extratropics, therefore stronger equatorial lower stratospheric upwelling, at HS in late winter. 
Figure 9 supports that the QBO not only modulates the solar signals in the NH polar region but also at low latitudes. It shows the correlation between $\mathrm{F}_{\mathrm{s} \text { Jul-Dec }}$ and $\mathrm{T}_{\text {Dec-Jan }}$ (upper panels) and between $\mathrm{F}_{\mathrm{s} \text { Sep-Feb }}$ and $\mathrm{T}_{\text {Feb-Mar }}$ (lower panels), under wQBO (left-hand panels) and eQBO (righthand panels), respectively, and suggest that the solar signals at low latitudes may also vary according to the QBO phase. In the upper stratosphere (1-5 hPa), the positive solar signals are stronger under wQBO while in the lower to middle stratosphere $(10-100 \mathrm{hPa})$, they are stronger under eQBO.

\section{[[Insert Figure 9]]}

The QBO modulated signals are shown clearly not only in the tropical lower stratosphere but also in the tropical upper stratosphere. The difference in the middle to lower stratosphere agrees well with Labitzke and van Loon (2000). The enhanced correlations in the upper stratosphere (at 1-2 hPa) under wQBO and in the middle to lower stratosphere under eQBO can be understood in terms of the QBO induced circulations (Plumb and Bell 1982; Baldwin et al. 2001), which are illustrated schematically by the grey arrows shown in the top row of Figure 9. In the upper stratosphere, the solar signals are likely to be radiatively driven as a result of irradiance changes and photolysis of ozone (Haigh 1996). In wQBO years, there is anomalous relative QBOinduced descent over the equator in the upper stratosphere $(\sim 2 \mathrm{hPa})$ with upwelling return arms in the subtropics. This results in additional adiabatic heating, thus reinforcing the positive solar signal near $2 \mathrm{hPa}$. In eQBO years the QBO induced circulation is in the opposite sense to that in wQBO years and thus the solar signal is reduced in the equatorial upper stratosphere near $2 \mathrm{hPa}$. Just below this level, however, the QBO-circulations reverse and the solar signal near $10 \mathrm{hPa}$ is enhanced in eQBO years but minimized in wQBO years. Thus, the distributions of solar signals 
above 10 hPa shown in Figure 9 precisely reflect the modulations due to QBO induced residual circulation.

In the lower stratosphere the solar signals are mainly dynamical in origin. A direct influence of dynamics on the temperature fields is reinforced by anomalous ozone transport at HS. An explanation of the anomalies in this region may involve SSWs and anomalous wave forcing in the polar region. In HS/wQBO years there are anomalously more SSWs occurring due to stronger poleward-propagating planetary waves, hence greater equatorial upwelling. The anomalously stronger equatorial upwelling under HS counteracts the anomalous wQBO descent. It results in weaker solar signals in the tropical lower stratosphere. In LS/eQBO years, there are also more SSWs occurring in the lower stratosphere mainly due to stronger poleward wave forcing under eQBO (Holton and Tan 1980; 1982; McIntyre 1982; Lu et al. 2008). However, the increased equatorial upwelling due to SSWs reinforces the anomalous QBO upwelling and hence the overall solar influence is strengthened in the equatorial lower stratosphere. These different mechanisms acting at the different heights may explain the observed asymmetries in figure 9 at all heights, in which the solar signals are enhanced in the upper stratosphere in wQBO years but are enhanced in the mid- and lower stratosphere in eQBO years. Nevertheless, it still does not explain why we observe more SSWs in HS/wQBO and LS/eQBO years in the mid- and lower stratosphere and why the planetary waves respond to the 11-yr SC differently in the early and late winters.

The physical processes discussed above suggests that the solar signal minimum at $10-30 \mathrm{hPa}$ is a result of different interactions between the QBO and the solar UV forcing in the upper and lower stratosphere. Lee and Smith (2003) have suggested that the lack of solar response in the tropical middle stratosphere is a result of linear superposition of two effects: the true solar 
response and the QBO contamination. Using a 2D model, Smith and Matthes (2008) found that the difficulty to isolate the solar cycle signals from the QBO signals lies in that the QBO tends to lead to a periodicity which is interpreted by linear statistical analyses as a component of the solar cycle. The strong positive subtropical correlations in the lower stratosphere under eQBO suggest that increased equatorial ascent and subtropical descent is associated with HS condition, supporting an increased descent rate of the easterly shear zone during solar maximum (Pascoe et al. 2005). Salby and Callaghan (2000) suggested a non-linear interaction between the 11-yr solar cycle and the QBO and found that while the length of easterly phase of the QBO was fairly constant, the westerly phase of the QBO varied according to the 11-yr solar cycle. However, Hamilton (2002), who examined 50 years of equatorial lower stratospheric wind observations from 1950 to 2000, found an apparent quasi-decadal variation in the duration of wQBO at 40-50 $\mathrm{hPa}$, but it was not in phase with the 11-yr SC. Using radiosonde measurements for the period of 1953-2005, Fischer and Tung (2008) found the correlations between the duration of the QBO and the 11-yr SC for either phase of the QBO were close to zero. Compared to the period of 1957-1990, oppositely-signed correlations were found to exist in the pre-1957 and post-1991 periods. Thus, whether the 11-yr SC has a non-linear, systematic influence on the QBO period length and descent speed remains inconclusive.

As demonstrated by considerably weaker correlations at low latitudes in Figures 1 and 3, further sensitivity tests using data from different time periods suggest weaker solar signals at low latitudes. This is largely because the temperature response in this region tends to be negative pre1978 (not shown). It is unclear whether this is due to lack of quality data in the pre-satellite era, or to influences from other sources of variability. The ENSO, major volcanic eruptions and increase of carbon dioxide may also influence the tropical ascending part of the BD circulation. 
Differences in the rate of ascent will result in changes in lower-stratospheric ozone concentrations and adiabatic temperature in the equatorial lower stratosphere. Previous studies have suggested that major volcanic eruptions will not change the general character of the temperature response to solar UV forcing (Lu et al. 2007). It is also unlikely for the ENSO to have a large influence on the solar signals at low latitudes as ENSO signals were found to be rather weak or negative in the lower stratosphere and insignificant in the upper stratosphere (Crooks and Gray 2005; García-Herrera et al. 2006; Camp and Tung 2007). This apparent sign switch in temperature responses to solar forcing in the late 70s might be related to a multidecadal oscillation in the NH. For instance, Lu et al. (2008) reported substantially weakened QBO signals in the Arctic stratosphere in 1977-1997 and suggested a possible relation to the regime shift over the North Pacific. Further research is required to answer the questions as to whether and how a multi-decadal oscillation might modulate the temperature responses to solar forcing.

\section{Conclusions}

This study examines the life cycle of the original Labitzke and van Loon (1988) QBO-SC relationship in the Northern Hemispheric (NH) winter by using daily ERA-40 reanalysis and ECMWF Operational data which extend vertically to $1 \mathrm{hPa}$. It is found that the QBO-SC relationship holds in both temperature and zonal wind throughout the period 1958-2006 and the solar signals primarily occur in late winter (February to March). In temperature, positive solar signals are found in the lower to middle polar stratosphere under wQBO and in the upper polar stratosphere under eQBO. In zonal wind, negative signals are found in the middle to upper stratosphere under wQBO and at mid-latitudes under eQBO. 
Additional insights into the QBO-SC relationship are put forward by studying its seasonal evolution. While the stratospheric signals are found in late January to early March, the tropospheric signals take place primarily in late March and early April. It is a result of a poleward and downward movement of solar induced anomalies since late January. In the Arctic winter, the life span of stratospheric solar signals is $\sim 30-50$ days, while it is $\sim 10$ days in the troposphere. Under wQBO, the polar stratospheric solar signals in zonal-mean zonal wind clearly lead and connect to those in the troposphere. In addition, the solar signals from the upper stratosphere tend to move faster and penetrate deeper down under wQBO than under eQBO.

Under WQBO, the solar perturbation on the NH winter circulation is likely to occur through its influence on SSWs in the polar region and compensating cooling at the equator in the upper stratosphere. Under eQBO, the negative signals in the lower stratosphere are likely due to more SSWs occurred in eQBO/LS years; a process similar to that under wQBO might hold true in the upper stratosphere. Thus, the strong solar signals in the upper to mid- polar stratosphere under eQBO represent a combined effect of recovery from SSWs occurring under eQBO/LS and positive temperature responses in the upper stratosphere during the HS years.

Changes in the stratospheric polar region are primarily driven by anomalous wave forcing and residual circulation, which can be influenced either by internally generated dynamical perturbations of the atmosphere (e.g. the ENSO and the QBO) or by external forcing (solar, volcanic eruption or increase of carbon dioxide). We find that the QBO-SC relationship becomes clearer when the ENSO is not strongly negative and such ENSO perturbation effect is more noticeable under eQBO than under wQBO. The relatively short data record poses a substantial challenge to properly separate ENSO influences from the QBO modulated solar signals as those 
effects are likely to be coupled non-linearly through their effects on the planetary waves and therefore the residual circulation.

At low latitudes, positive solar signals are found in the stratospheric temperature fields, regardless of the QBO phase. The signals tend to have a longer life span ( 3- 4 months) and are characterized by a vertical double-peaked structure. The location and the magnitude of the positive equatorial response are in general agreement with previous studies (Crooks and Gray 2005; Remsberg and Deaver 2005; Keckhut et al. 2005). For the first time, however, we find that the lower stratospheric solar signals tend to be stronger in early winter but weaker in late winter. This is likely due to more waves being refracted toward the polar stratosphere at HS in late winter.

The solar signals at low latitudes are found to also vary according to the QBO phase. The temperature response in the lower stratosphere agrees well with that shown previously by Labitzke (2004, 2005), who reported a similar QBO-SC modulation in the same region during the NH summer. Here we suggest that the significantly enhanced solar signals in the upper stratosphere (at 1-2 hPa) under wQBO and in the middle to lower stratosphere under eQBO can be explained in terms of the QBO induced circulations in the upper stratosphere, and combined effects of SSWs and QBO induced circulation in the lower stratosphere.

Further sensitivity tests suggest that, while the polar QBO-SC relationship remains stable for the entire period of 1958-2006, the signals in low-latitude temperature appear to be only significant when data from the satellite era were used. Longer data records and a better understanding of the interaction between solar forcing and various types of atmospheric variability are needed to determine the exact magnitude and structure of solar responses in temperature near the equator. 
Acknowledgements: HL and MJJ were supported by the UK Natural Environment Research Council (NERC). LJG was supported by the UK NERC National Centre for Atmospheric Science (NCAS). MPB was funded by NSF under the US CLIVAR program and the Office of Polar Programs. We are grateful to two anonymous reviewers for their constructive comments. 


\section{References}

Baldwin MP, Dunkerton TJ. 1998. Biennial, quasi-biennial, and decadal oscillations of potential vorticity in the northern stratosphere. J. Geophys. Res. 103: 3919-3928.

Baldwin MP. 2001. Annular modes in global daily surface pressure. Geophys. Res. Lett. 28: 4115-4118.

Baldwin MP, Dunkerton TJ. 2001. Stratospheric harbingers of anomalous weather regimes. Science 294: 581-584.

Baldwin MP, Gray LJ, Dunkerton TJ, Hamilton K, Haynes PH, Randel WJ, Holton J R, Alexander MJ, Hirota I, Horinouchi T, Jones BA, Kinnersley JS, Marquardt C, Sato K, Takahasi M. 2001.The quasibiennial oscillation. Rev. Geophys. 39: 179-229.

Camp CD, Tung KK. 2007. Stratospheric polar warming by ENSO in winter: A statistical study, Geophys. Res. Lett. 34: L04809, doi:10.1029/2006GL028521.

Crooks SA, Gray LJ. 2005. Characterization of the 11-year solar signal using a multiple regression analysis of the ERA-40 dataset. J. Clim. 18: 996-1015.

Fischer P, Tung KK. 2008. A reexamination of the QBO period modulation by the solar cycle. $J$. Geophys. Res. 113: D07114, doi:07110.01029/02007JD008983.

García-Herrera R, Calvo N, Garcia RR, Giorgetta MA. 2006. Propagation of ENSO temperature signals into the middle atmosphere: A comparison of two general circulation models and ERA-40 reanalysis data. J. Geophys. Res. 111: D06101. doi:10.1029/2005JD006061.

Gray LJ, Phipps SJ, Dunkerton TJ, Baldwin MP, Drysdale EF, Allen MR. 2001. A data study of the influence of the equatorial upper stratosphere on northern-hemisphere stratospheric sudden warmings. Q. J. R. Meteorol. Soc. 127: 1985-2003.

Gray LJ, Crooks SA, Pascoe C, Sparrow S, Palmer M. 2004. Solar and QBO influences on the timing of stratospheric sudden warmings. J. Atmos. Sci. 61: 2777-2796.

Gray LJ, Rumbold ST, Shine KP. 2009. Stratospheric temperature and radiative forcing response to the 11-year solar cycle changes in irradiance and ozone. J. Atmos. Sci. (submitted).

Haigh JD. 1996. The impact of solar variability on climate. Science 272: 981-984.

Haigh JD. 1999. A GCM study of climate change in response to the 11-year solar cycle. Q. J. R. Meteorol. Soc. 125: 871-892. 
Haigh JD. 2003. The effects of solar variability on the Earth's climate. Philos. Trans. R. Soc. Lond. Ser. A-Math. Phys. Eng. Sci. 361: 95-111.

Hamilton K. 2002. A note on the quasi-decadal modulation of the stratospheric QBO period. J. Clim. 15: 2562-2565.

Holton JR, Tan HC. 1980. The influence of the equatorial quasi-biennial oscillation on the global circulation at 50 mb. J. Atmos. Sci. 37: 2200-2208.

Holton JR, Tan HC. 1982. The quasi-biennial oscillation in the Northern Hemisphere lower stratosphere. J. Meteor. Soc. Japan 60: 140-148.

Hood LL. 2004. Effects of solar UV variability on the stratosphere. In: Solar variability and its effect on the Earth.s atmosphere and climate system. Edited by J. Pap, et al. AGU Monograph Series, Washington D.C.

Keckhut P, Cagnazzo C, Chanin ML, Claud C, Hauchecorne A. 2005. The 11-year solar-cycle effects on temperature in the upper stratosphere and mesosphere Part I: Assessment of observations. J. Atmos. Sol.-Terr. Phys. 67: 940-947.

Kodera K, Kuroda Y. 2002. Dynamical response to the solar cycle. J. Geophys. Res. 107: D4749. DOI: 4710.1029/2002JD002224.

Labitzke K. 1987. Sunspots, the QBO, and the stratospheric temperature in the north polar-region. Geophys. Res. Lett. 14: 535-537.

Labitzke K, van Loon H. 1988. Associations between the 11-year solar-cycle, the QBO and the atmosphere 1. The troposphere and stratosphere in the Northern Hemisphere in winter. J. Atmos. Terr. Phys. 50: 197-206.

Labitzke K, van Loon H. 2000. The QBO effect on the solar signal in the global stratosphere in the winter of the Northern Hemisphere. J. Atmos. Sol.-Terr. Phys. 62: 621-628.

Labitzke K. 2001. The global signal of the 11-year sunspot cycle in the stratosphere: Differences between solar maxima and minima. Meteorol. Zeitschrift 10: 83-90.

Labitzke K. 2004. On the signal of the 11-year sunspot cycle in the stratosphere and its modulation by the quasi-biennial oscillation. J. Atmos. Sol.-Terr. Phys. 66: 1151-1157.

Labitzke K. 2005. On the solar cycle-QBO relationship: A summary. J. Atmos. Sol.-Terr. Phys. 67: 45-54.

Labitzke K, Kunze M, Bronnimann S. 2006. Sunspots, the QBO and the stratosphere in the North Polar Region - 20 years later. Meteorol. Zeitschrift 15: 355-363. 
Lee H, Smith AK. 2003. Simulation of the combined effects of solar cycle, quasi-biennial oscillation, and volcanic forcing on stratospheric ozone changes in recent decades. J. Geophys.Res. 108: 4049. doi:10.1029/2001JD001503.

Limpasuvan V, Thompson DWJ, Hartmann DL. 2004. The life cycle of the Northern Hemisphere sudden stratospheric warmings. J. Clim. 17: 2584-2596.

Lu H, Jarvis MJ, Graf H-F, Young PC, Horne RB. 2007. Atmospheric temperature response to solar irradiance and geomagnetic activity. J. Geophys. Res. 112: D11109. DOI: 11110.11029/12006JD007864.

Lu H, Baldwin MP, Gray LJ, Jarvis MJ. 2008. Decadal-scale changes in the effect of the QBO on the northern stratospheric polar vortex. J. Geophys. Res. 113: D10114. DOI: 10110.11029/12007JD009647.

McCormack JP. 2003. The influence of the 11-year solar cycle on the quasi-biennial oscillation. Geophys. Res. Lett. 30: 2162. DOI: 10.1029/2003GL018314.

McCormack JP, Siskind DE, Hood LL. 2007. Solar-QBO interaction and its impact on stratospheric ozone in a zonally averaged photochemical transport model of the middle atmosphere. J. Geophys. Res. 112: D16109. DOI: 10.1029/2006JD008369.

McIntyre ME. 1982. How well do we understand the dynamics of stratospheric warmings? J. Meteor. Soc. Japan 60: 37-65.

Naito Y, Hirota I. 1997. Interannual variability of the northern winter stratospheric circulation related to the QBO and the solar cycle. J. Meteor. Soc. Japan 75: 925-937.

Naito Y, Taguchi M, Yoden S. 2003. A parameter sweep experiment on the effects of the equatorial QBO on stratospheric sudden warming events. J. Atmos. Sci. 60: 1380-1394.

Newman PA, Rosenfield JE. 1997. Stratospheric thermal damping times. Geophys. Res. Lett. 24: 433436.

Pascoe CL, Gray LJ, Crooks SA, Juckes MN, Baldwin MP. 2005. The quasi-biennial oscillation: Analysis using ERA-40 data. J. Geophys. Res. 110: D08105. DOI: 08110.01029/02004JD004941.

Plumb RA, Bell RC. 1982. A model of the quasi-biennial oscillation on an equatorial beta-plane. Q. J. R. Meteorol. Soc. 108: 335-352.

Randel WJ. 1993. Global variations of zonal mean ozone during stratospheric warming events. J. Atmos. Sci. 50: 3308-3321. 
Randel WJ, Wu F, Stolarski R. 2002. Changes in column ozone correlated with the stratospheric EP flux. J. Meteor. Soc. Japan 80: 849-862.

Remsberg EE, Deaver LE. 2005. Interannual, solar cycle, and trend terms in middle atmospheric temperature time series from HALOE. J. Geophys. Res. 110: D06106. doi:10.1029/2004JD004905.

Salby ML, Callaghan PF. 2000. Connection between the solar cycle and the QBO: The missing link. J. Clim. 13: 2652-2662.

Salby ML, Callaghan PF. 2004. Evidence of the solar cycle in the general circulation of the stratosphere. J. Clim. 17: 34-46.

Salby ML, Callaghan PF. 2006. Relationship of the quasi-biennial oscillation to the stratospheric signature of the solar cycle. J. Geophys. Res. 111: D06110. DOI: 01029/02005JD006012.

Smith AK, Matthes K. 2008. Decadal-scale periodicities in the stratosphere associated with the solar cycle and the QBO, J. Geophys. Res. 113: D05311, doi:10.1029/2007JD009051.

Thompson DWJ, Wallace JM. 1998. The arctic oscillation signature in the wintertime geopotential height and temperature fields. Geophys. Res. Lett. 25: 1297-1300.

Uppala SM et al. 2005. The ERA-40 reanalysis. Q. J. R. Meteorol. Soc. 131: 2961-3012. 


\section{Figure Captions}

Figure 1. Latitude - height cross-section of correlations between monthly-averaged zonal mean temperature and 6-month averaged F10.7-cm solar flux $\left(F_{s}\right.$ with units of $\left.10^{-22} \mathrm{w} \mathrm{m}^{-2} \mathrm{~Hz}^{-1}\right)$ preceding the temperature averages for all years (the $1^{\text {st }}$ column), under wQBO (the $2^{\text {nd }}$ column), and under eQBO (the $3^{\text {rd }}$ column). Top row: February, bottom row: March. The number of data points (i.e. years) used to calculate the correlation coefficients $(r)$ are indicated on the top of each panel. Red solid, blue dotted and black dotted lines are positive, negative and zero correlations, respectively. The contour interval is \pm 0.1 . Shaded areas denote confidence levels above 95\%, calculated using standard one-sided $t$-test.

Figure 2. Time series of the 6-month averaged F10.7-cm solar flux ( $F_{s}$, the dash line) and the deseasonalized February temperature at $85^{\circ} \mathrm{N}$, at $50 \mathrm{hPa}$ under (a) wQBO (the solid line) and (b) at 150 hPa under eQBO (the solid line) (b). The correlation coefficients and statistical confidence levels (in bracket) are shown in the top of each panel.

Figure 3. Same as Figure 1 but the temperatures are replaced by the zonal winds.

Figure 4. Same as Figure 2 but for the deseasonalized zonal-mean zonal wind at $70^{\circ} \mathrm{N}, 10 \mathrm{hPa}$ under wQBO (a), and at $70^{\circ} \mathrm{N}, 100 \mathrm{hPa}$ under eQBO (b).

Figure 5. Running correlations between the 6-month averaged $F_{s}$ and temperature at $90^{\circ} \mathrm{N}$ (upper row), and zonal wind at $80^{\circ} \mathrm{N}$, under wQBO (the $1^{\text {st }}$ column) and under eQBO (the $2^{\text {nd }}$ column), displayed in time-height cross section. The QBO, polar temperature and zonal-mean zonal wind are averaged using a 10-day running window and $F_{s}$ is defined as 6-month averaged values of F10.7-cm solar radio flux proceeding the averages of atmospheric variables. Solid and dashed contours represent positive and negative correlation and the thick black contour is zero correlation. The contour interval is \pm 0.1 . The light and dark shaded areas indicate that the correlations are statistical significant with confidence level $\geq$ $90 \%$ and $95 \%$, respectively. Similar results can be obtained from $65^{\circ} \mathrm{N}$ poleward. 
Figure 6. Seasonal progression of the correlations between the NH winter (November through March) temperature and 6-month averaged F10.7-cm solar flux, displayed in latitude-height cross-section. $1^{\text {st }}$ and $2^{\text {nd }}$ columns: QBO westerly and easterly phases for the period of $1^{\text {st }}$ November to $10^{\text {th }}$ of January; $3^{\text {rd }}$ and $4^{\text {th }}$ columns: QBO westerly and easterly phases for the period of $11^{\text {th }}$ January to $20^{\text {th }}$ of March. The contours and shaded areas are the same as Figure 1.

Figure 7. Same as Figure 6 but the temperatures are replaced by the zonal winds.

Figure 8. Composite differences between HS and LS for temperature $\Delta \mathrm{T}$ (K, right-hand panels) for the December-January mean (a) and February-March mean (b), displayed in the NH meridional-vertical cross section of stratospheric extra-polar region. The data are grouped into $\geq \bar{F}_{s}$ and $<\overline{F_{s}}$, where $\overline{F_{s}}$ is July to December (in (a)) and September to February (in (b)) averaged F10.7-cm solar flux. The areas enclosed within the grey dashed and solid lines indicate that the differences are statistically significant from zero with confidence levels of $90 \%$ and $95 \%$, respectively, calculated using a Monte Carlo trial based non-parametric test.

Figure 9. Correlations between December-January (the $1^{\text {st }}$ row), and February-March (the $2^{\text {nd }}$ row) mean temperature and 6-month averaged F10.7-cm solar flux, under wQBO (the $1^{\text {st }}$ column), and under eQBO (the $2^{\text {nd }}$ column), displayed in the $\mathrm{NH}$ meridional-vertical cross section of stratospheric extra-polar region. The contours and shaded areas are the same as Figure 1 . The grey arrows shown in the top row panels illustrate the directions of the QBO induced circulations. 

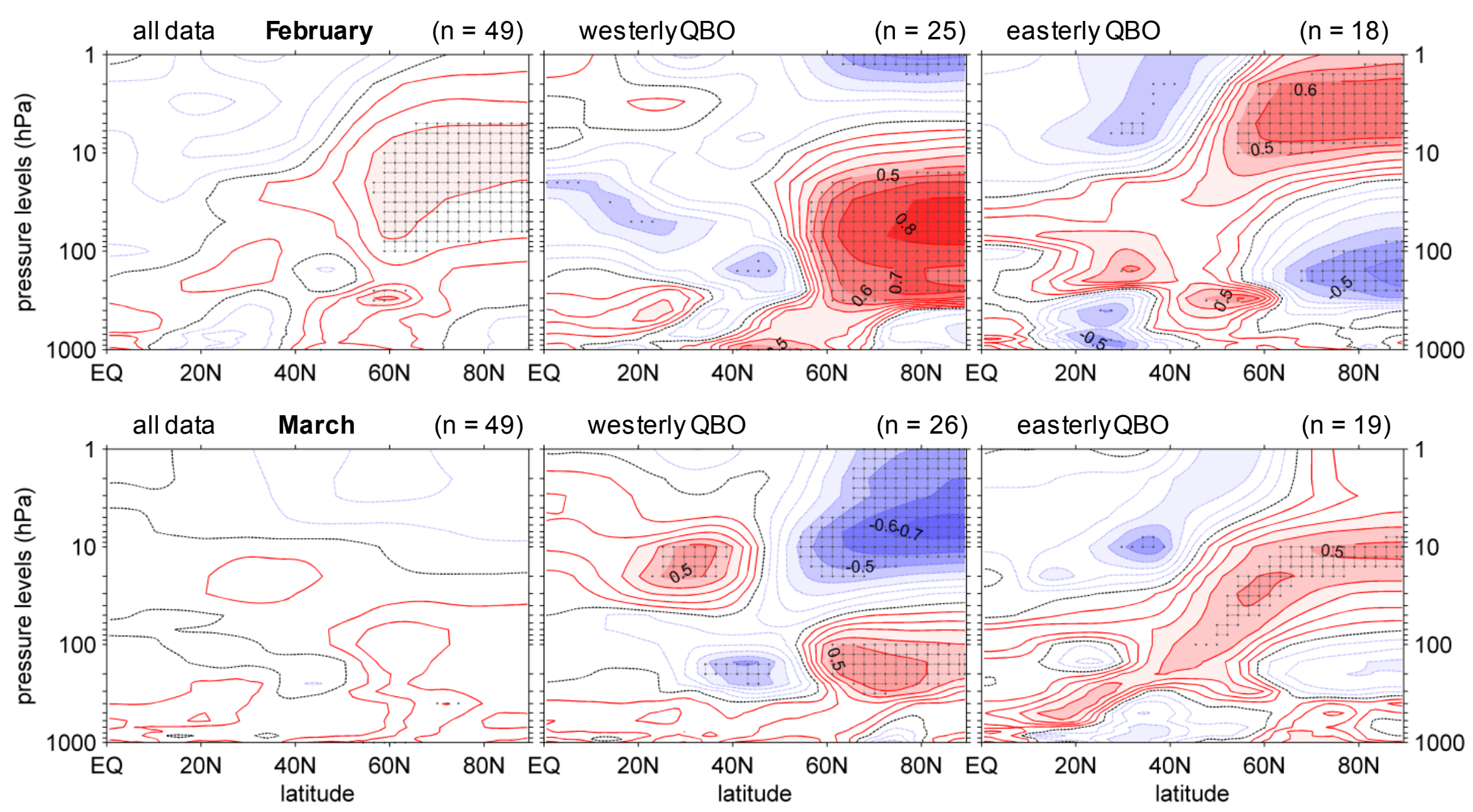

Figure 1 


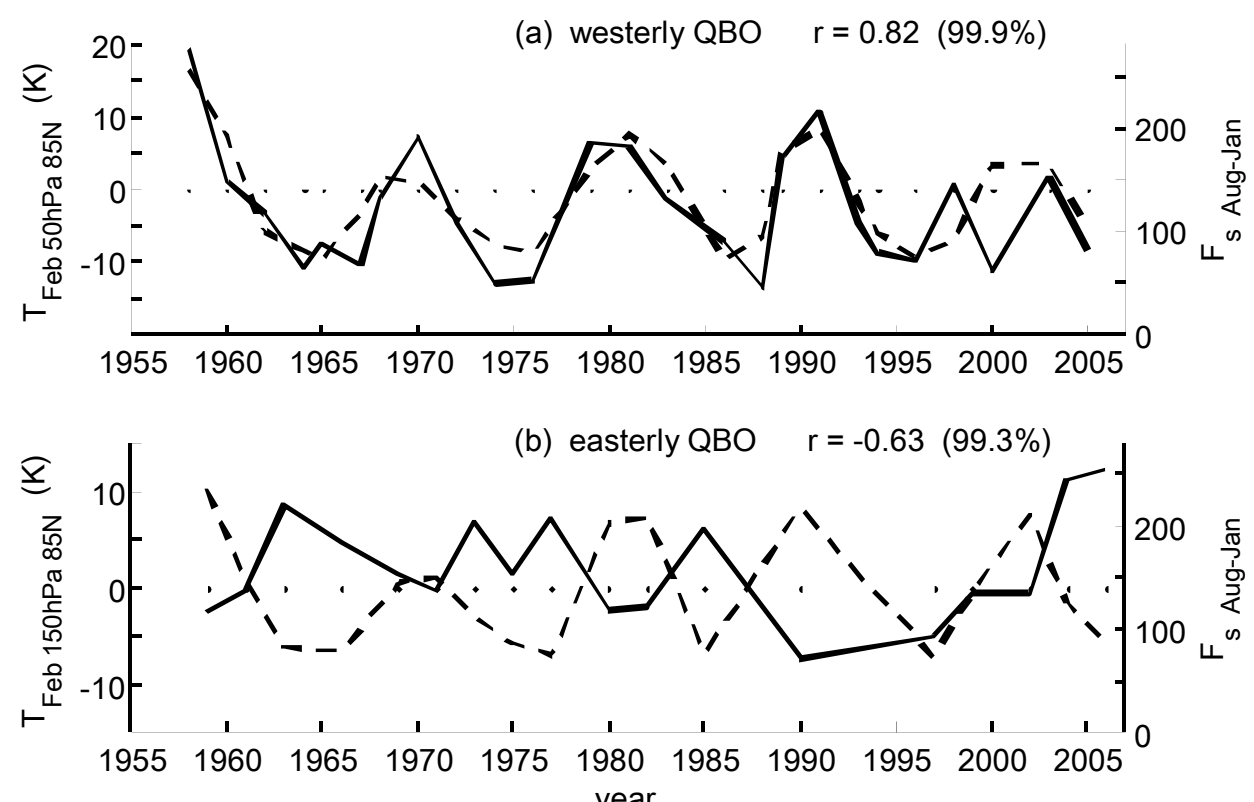

Figure 2 

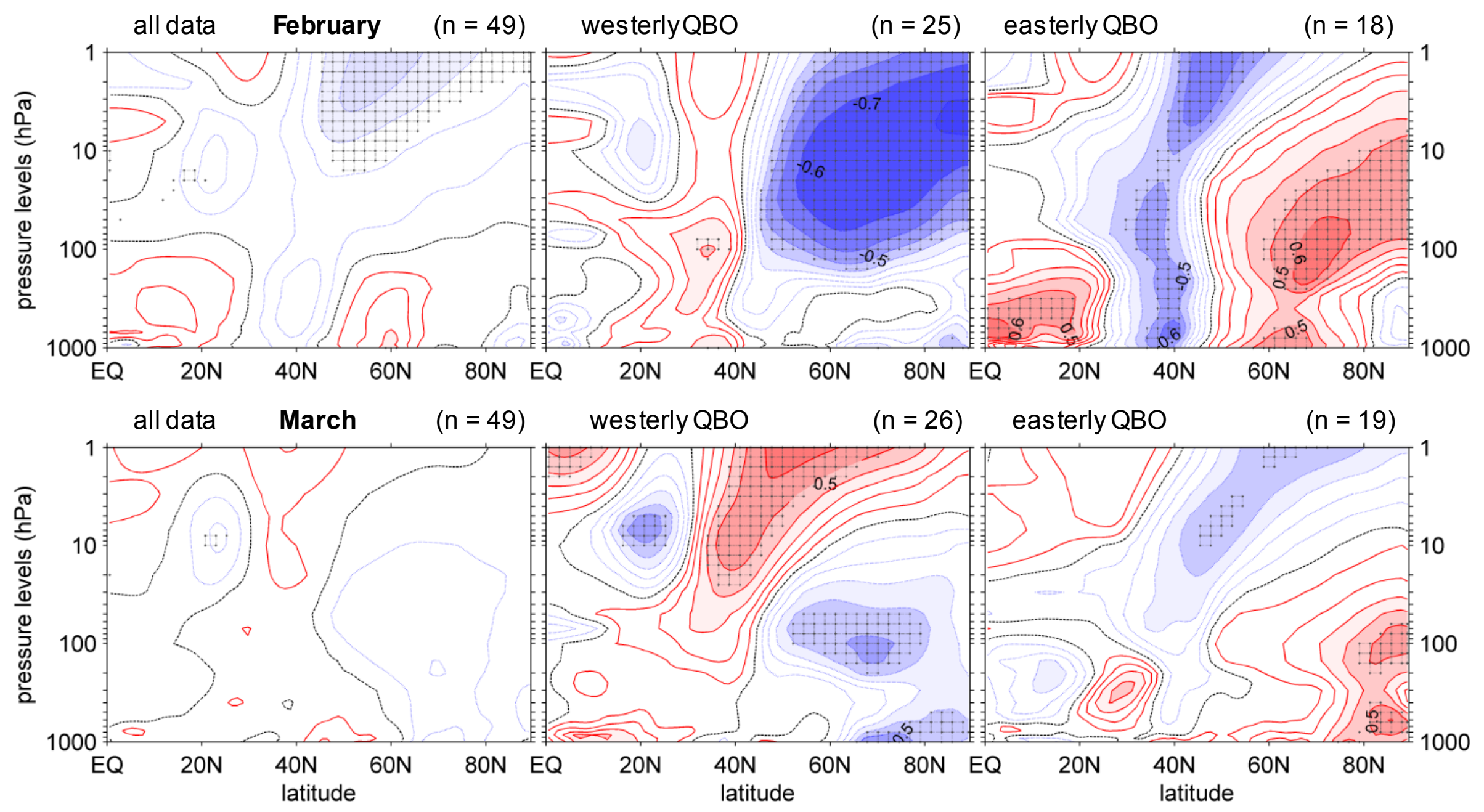

Figure 3 


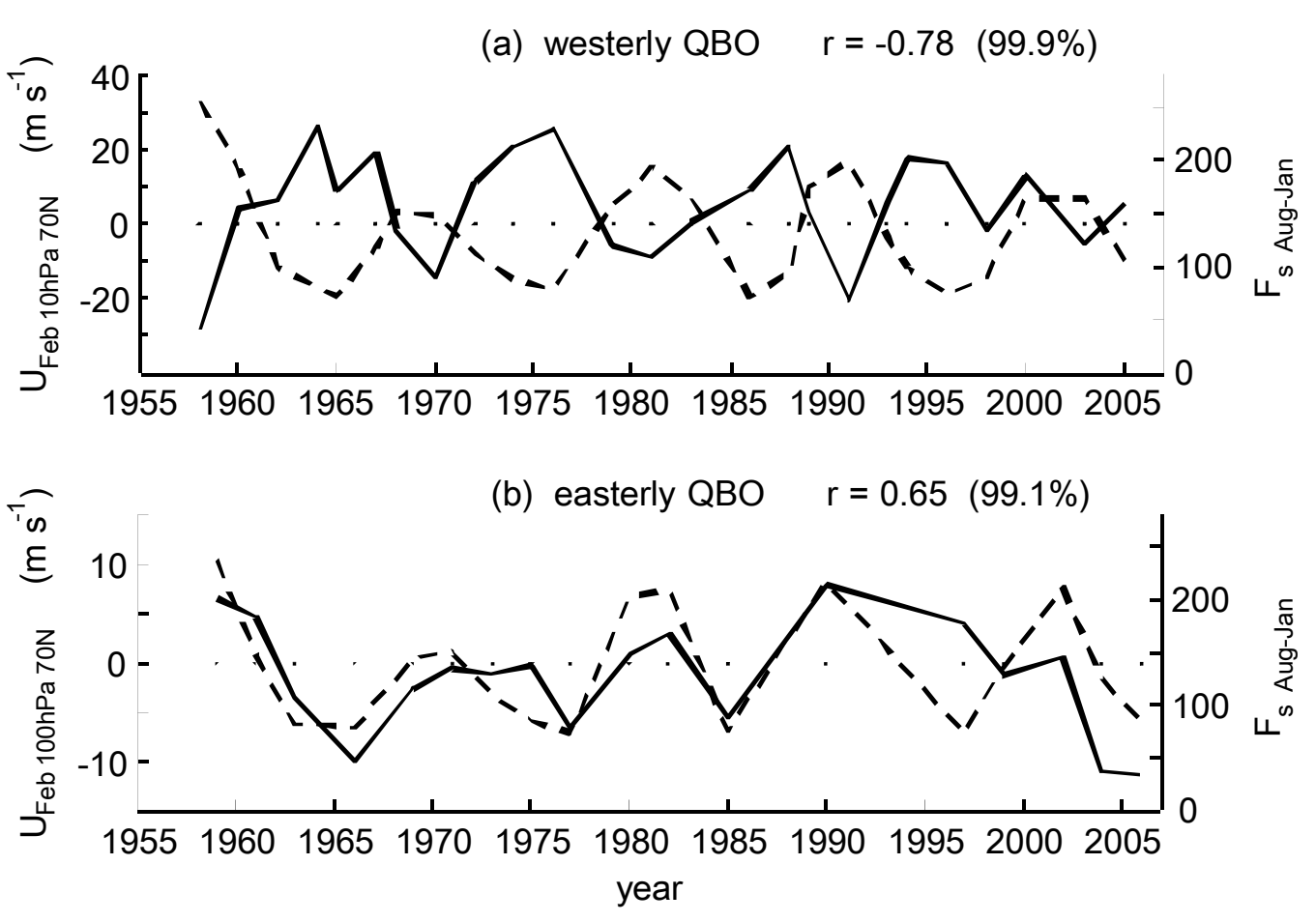

Figure 4 

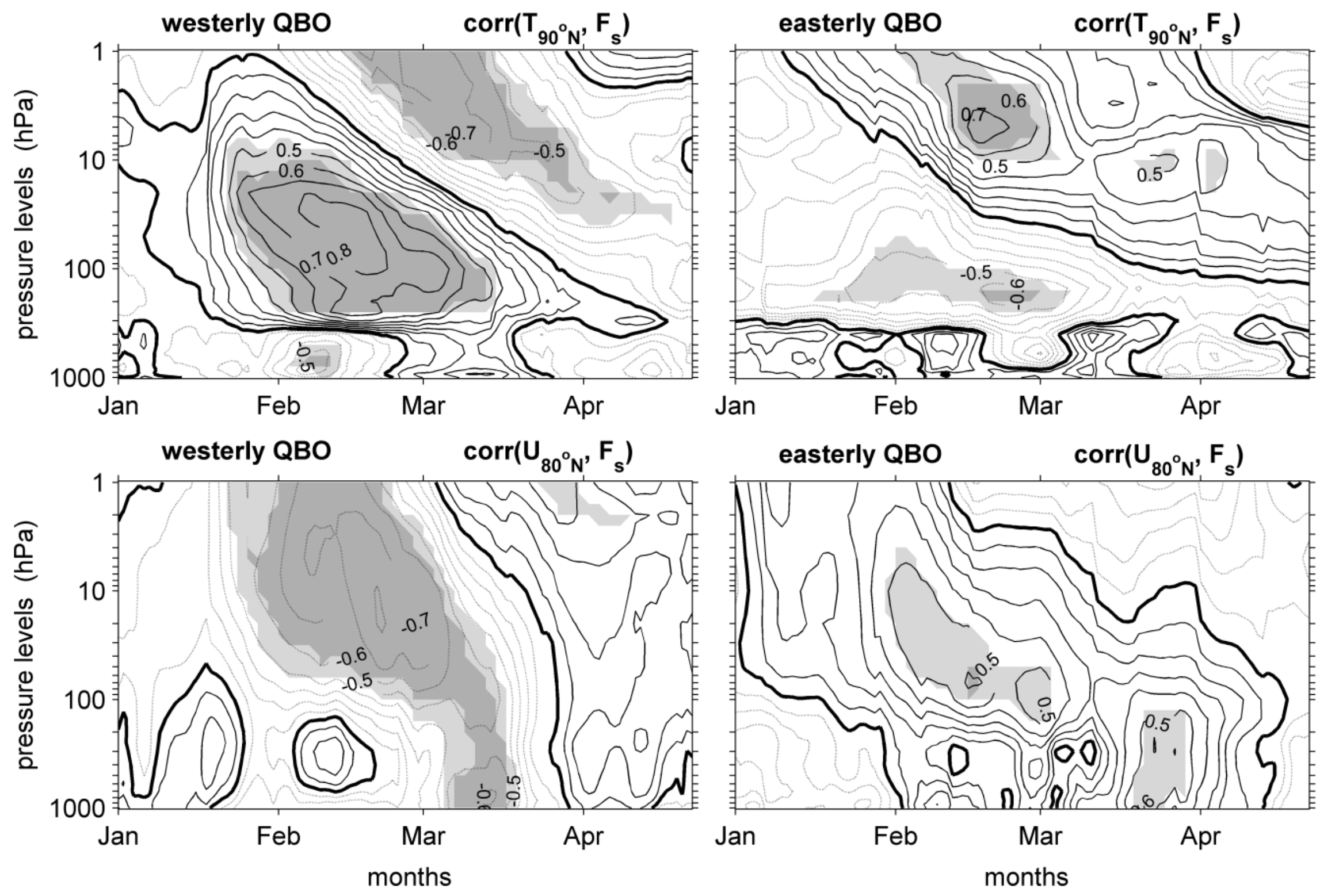

Figure 5 


\section{westerly QBO}
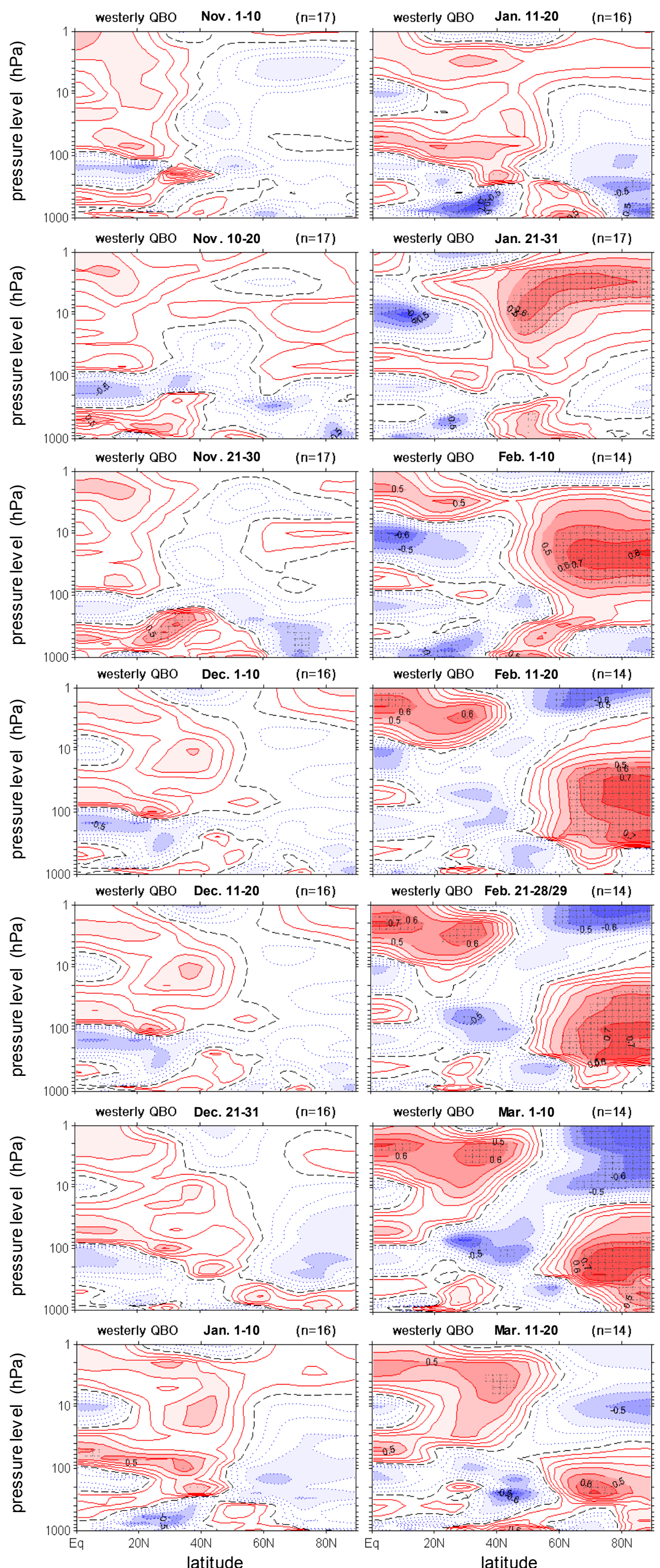

easterly QBO
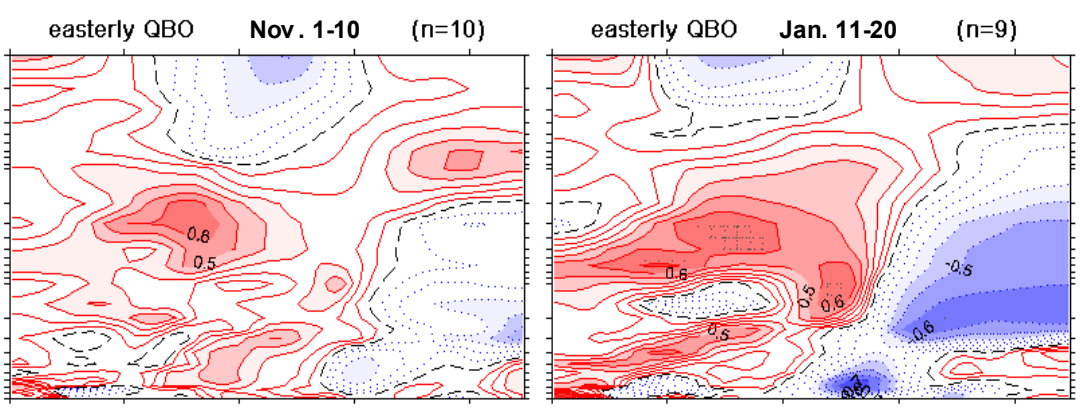

easterly QBO Nov. 10-20 (n=10)

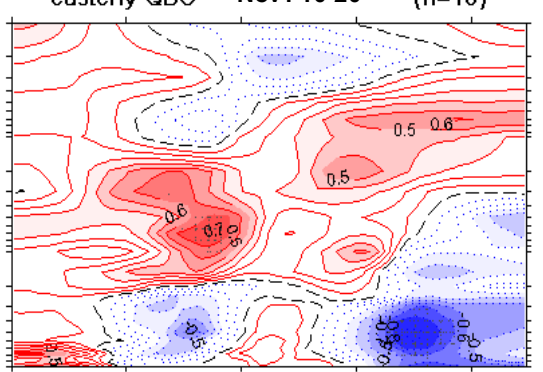

easterly QBO Jan. 21-31 $(\mathrm{n}=9)$

easterly QBO Nov. 21-30 $\quad(n=10)$
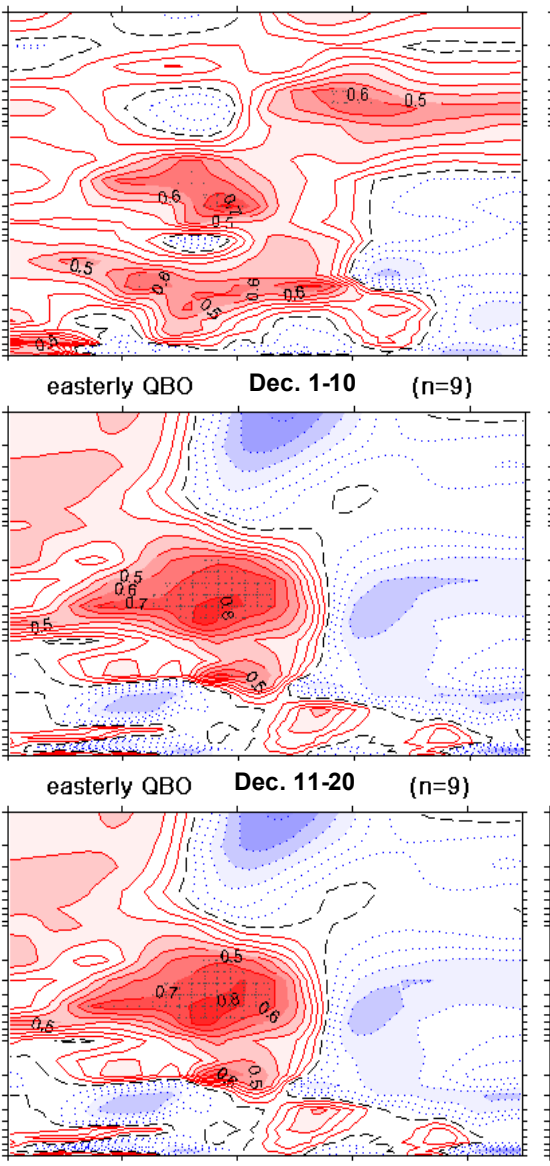

easterly QBO Dec. 21-31 (n=9)
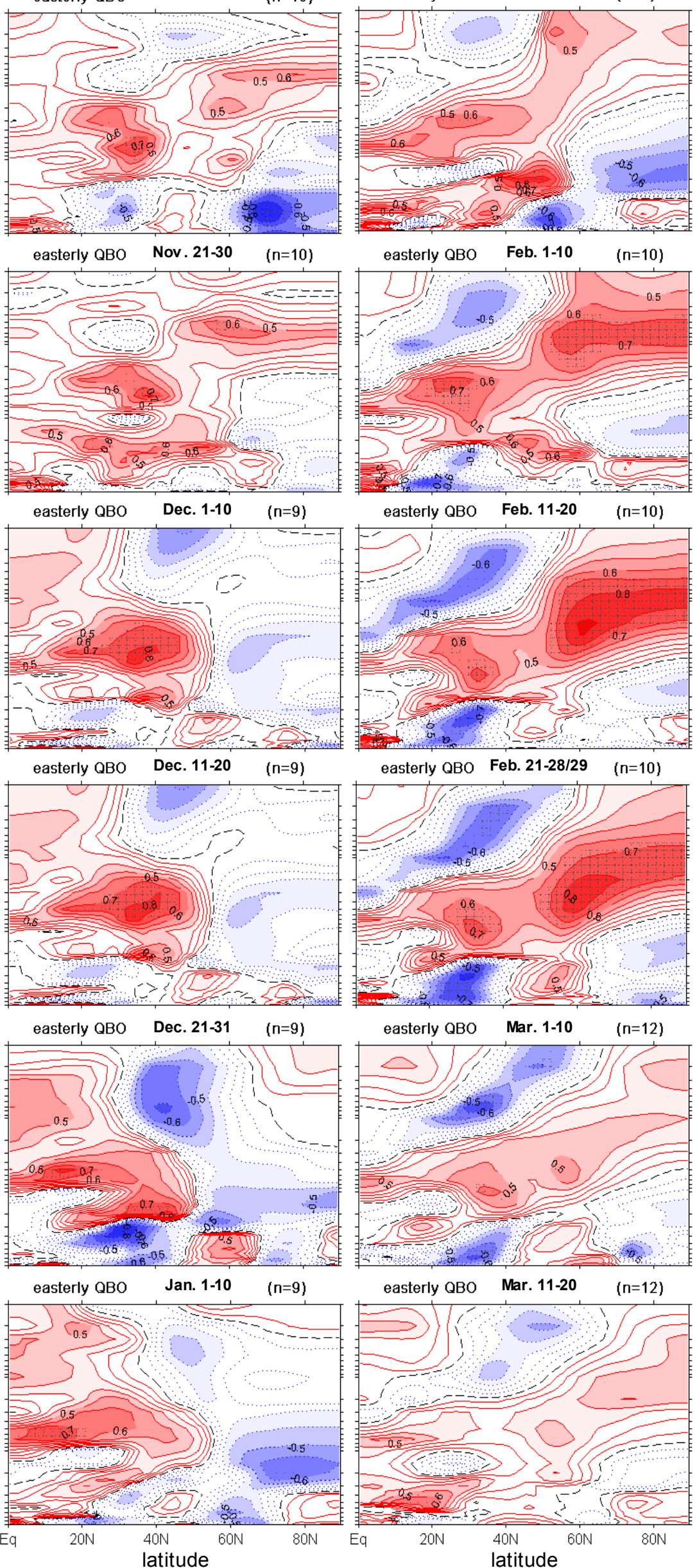

easterly QBO Feb. 11-20 $\quad(n=10)$

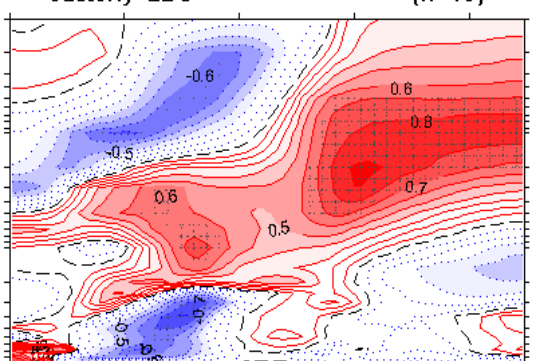

easterly QBO Feb. 21-28/29 ( $\mathrm{n=10)}$

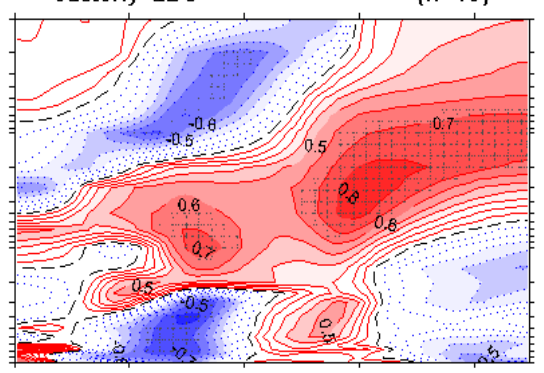

easterly QBO Mar. 1-10 (n=12)
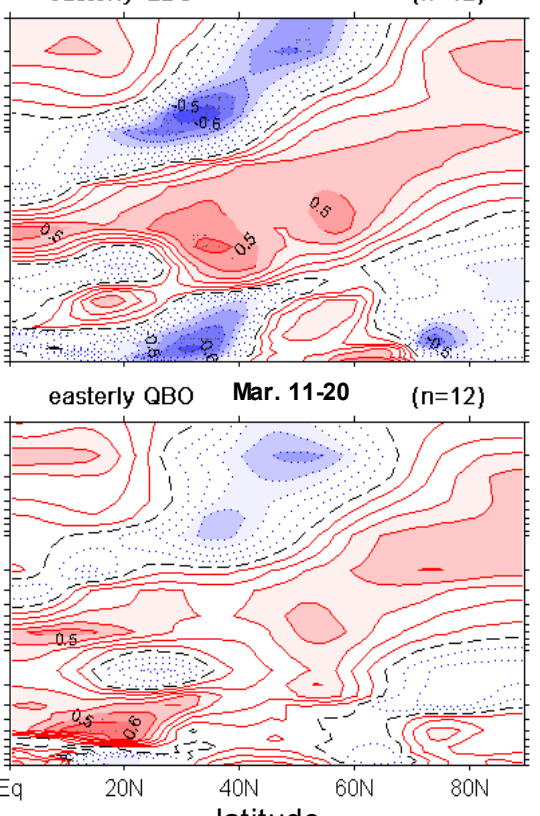
westerly QBO
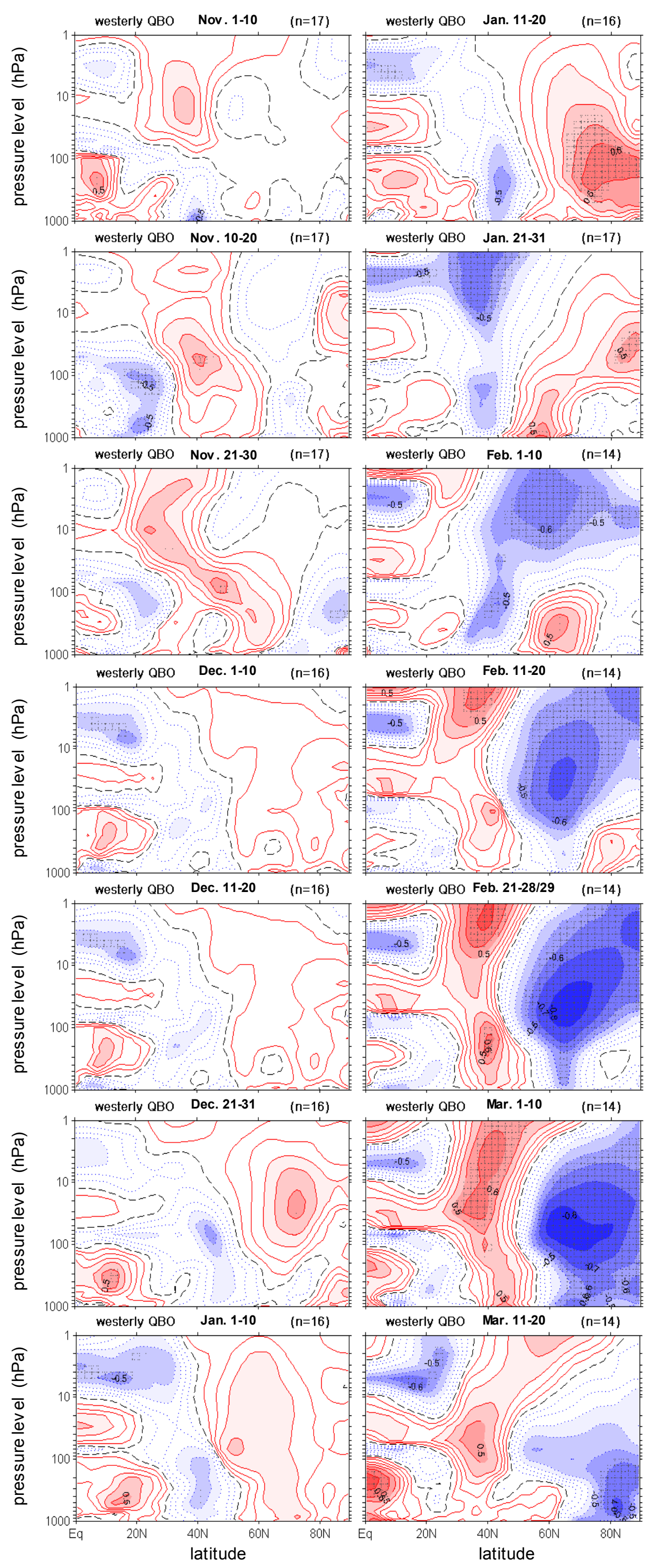

easterly QBO
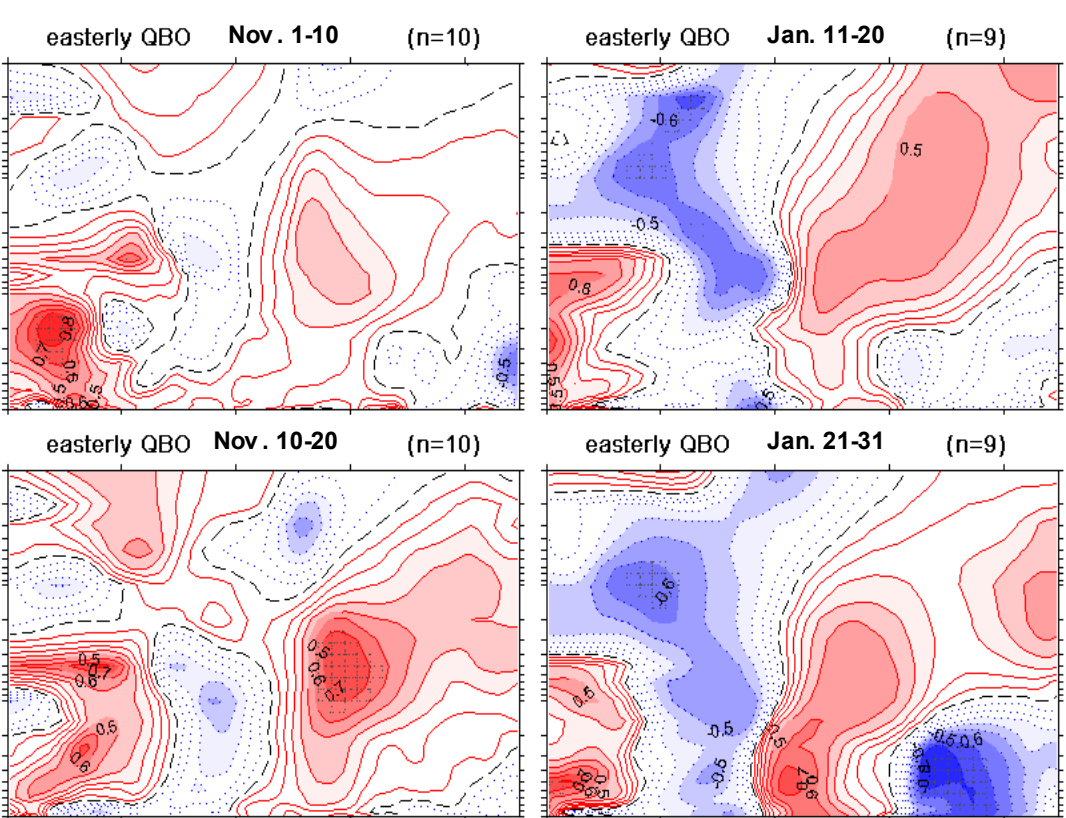

easterly QBO Jan. 21-31 (n=9)

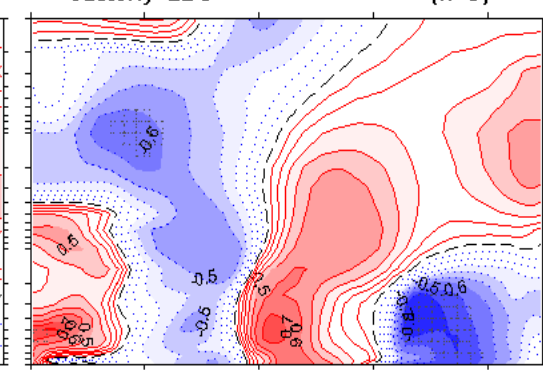

easterly OBO Nov. 21-30 (n=10)
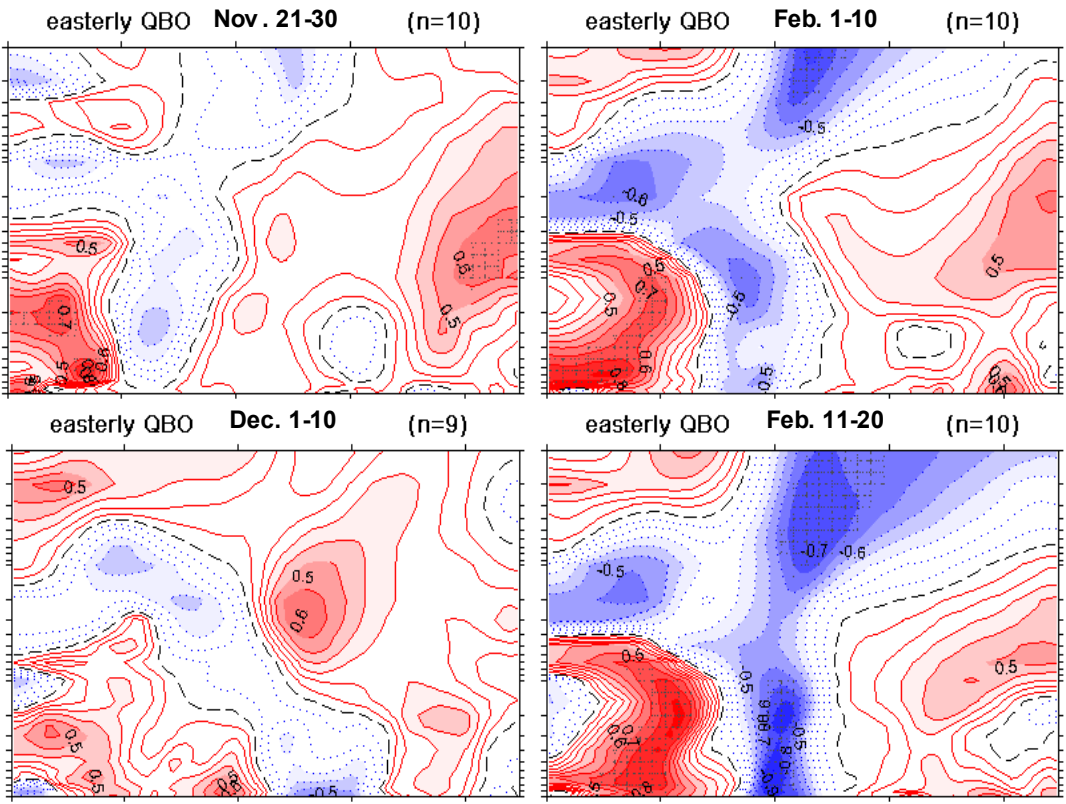

easterly QBO Dec. 11-20 (n=9)

easterly QBO Feb. 21-28/29 (n=10)
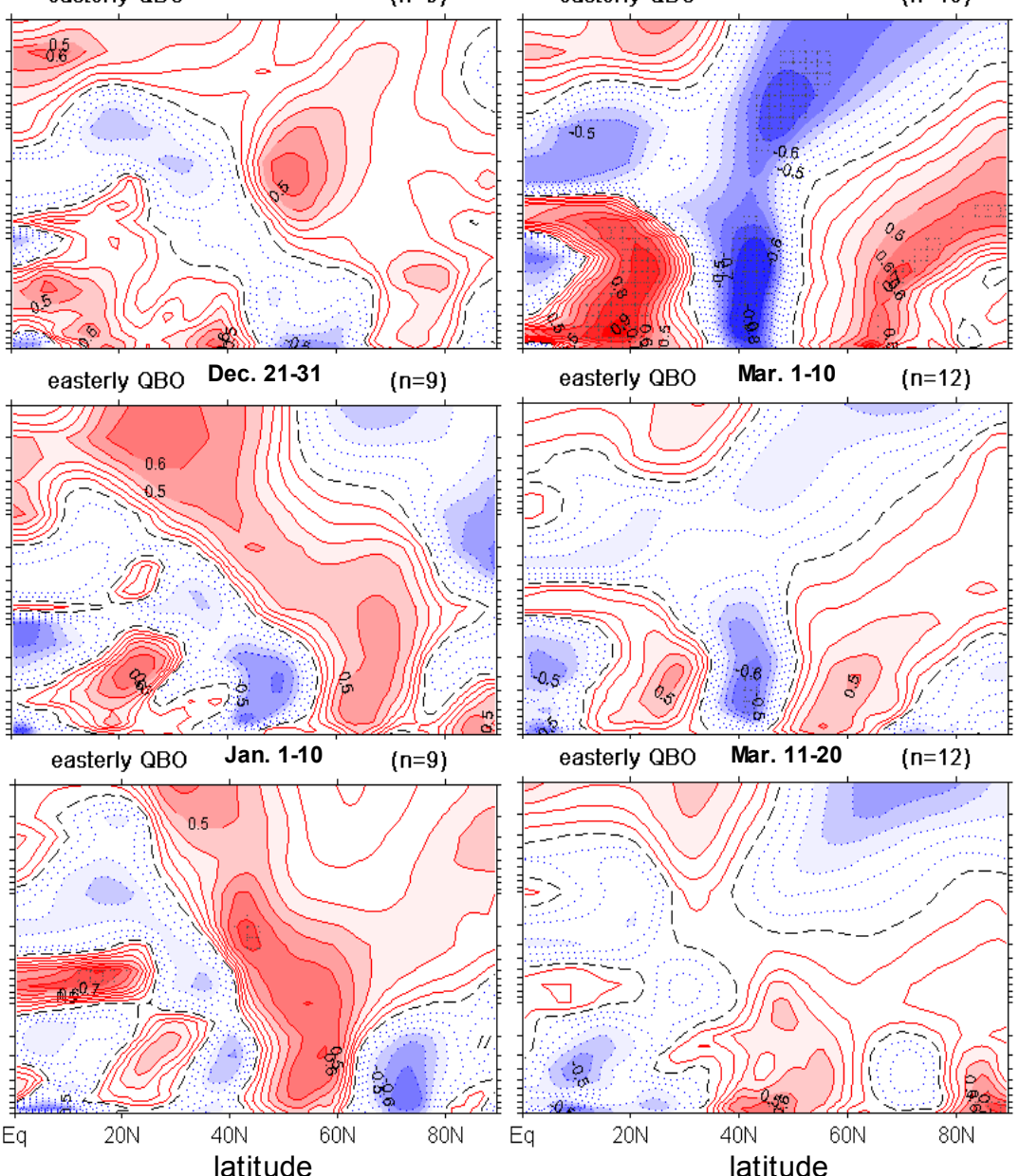
(a) $\Delta T_{\text {Dec-Jan }}$

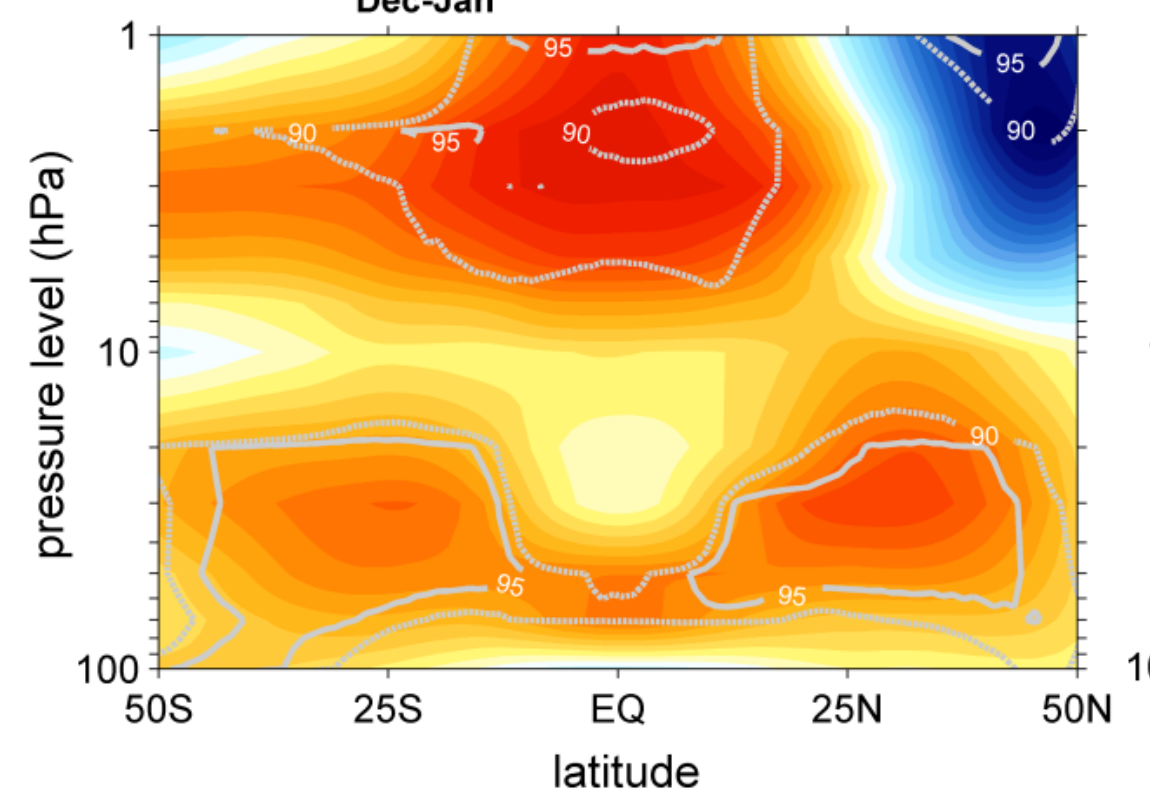

(b) $\Delta T_{\text {Feb-Mar }}$

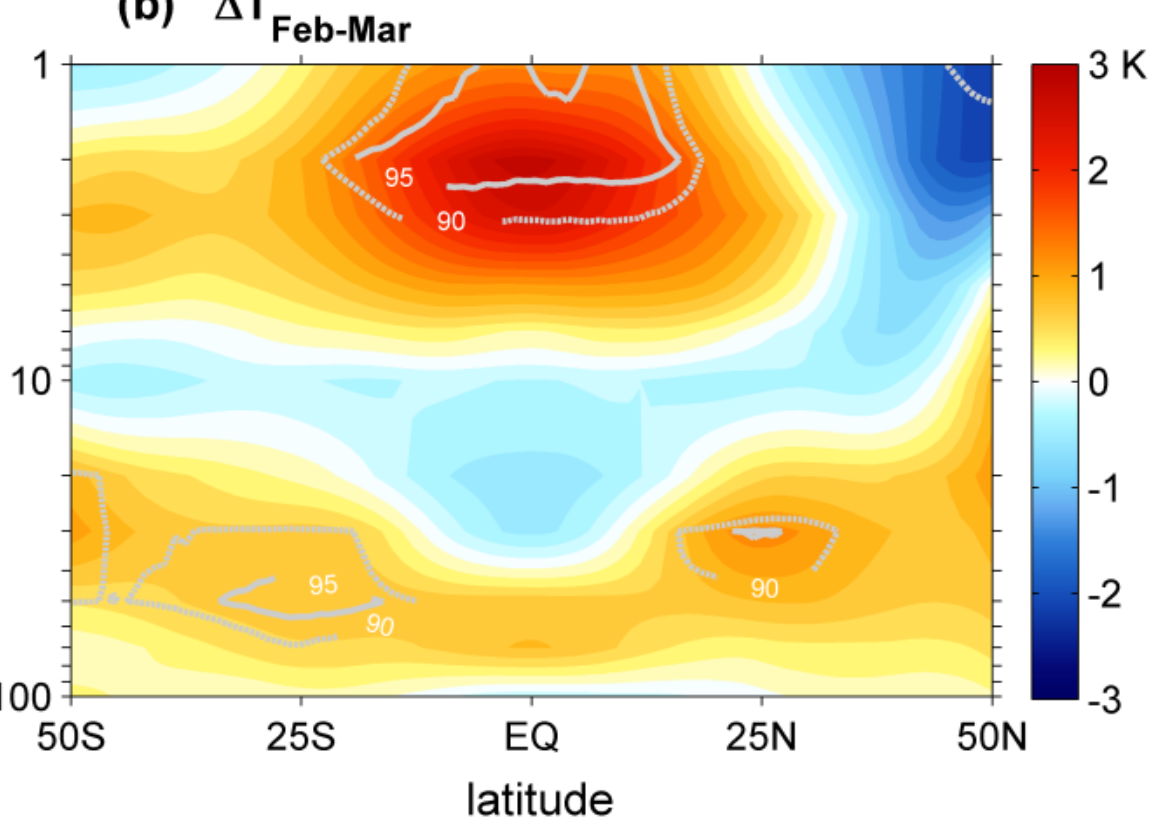

Figure 8 

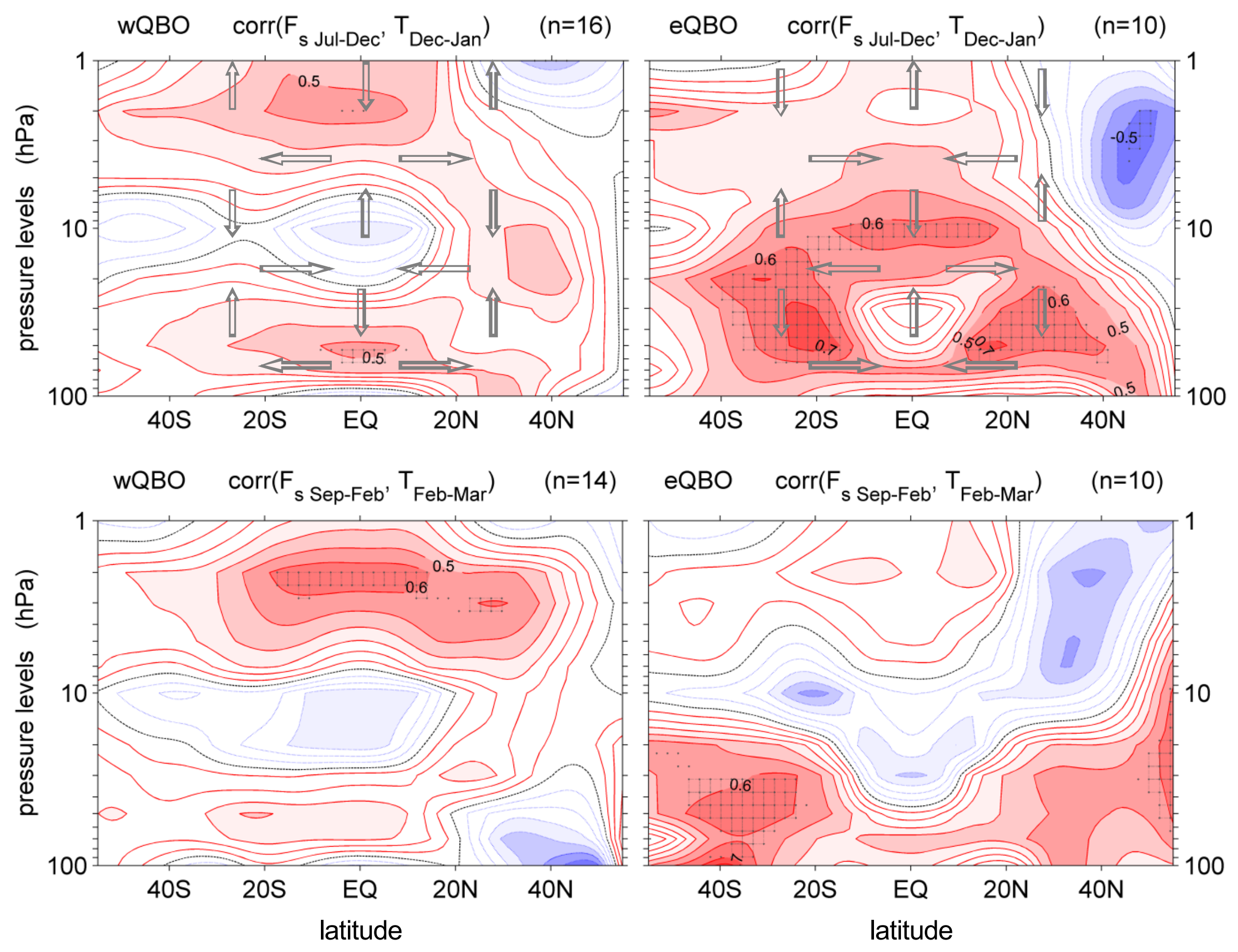

Figure 9 